\title{
COPING WITH UNCERTAINTY: COST-BENEFIT ANALYSIS, THE PRECAUTIONARY PRINCIPLE, AND CLIMATE CHANGE
}

\author{
Daniel A. Farber*
}

Abstract: Climate scientists are confident that greenhouse gases are causing climate change, but it is difficult to predict the severity of future climate change or its local impacts. Unfortunately, we cannot wait for these uncertainties to be resolved before addressing the issue of climate change. Policymakers use two different strategies for setting climate policy in the face of this uncertainty: cost-benefit analysis and the precautionary principle. Although there has been much discussion of these strategies in the abstract, there has been less effort to assess them in operation.

This Article analyzes these strategies and considers their application to climate risks in four case studies: determination of the social cost of carbon, international endorsement of a $2{ }^{\circ} \mathrm{C}$ ceiling on warming, the Environmental Protection Agency's endangerment finding, and the polar bear listing decision. The precautionary principle requires that feasible steps be taken to control risks in the face of uncertainty. This proposal works well in determining whether to regulate, but gives limited guidance about the appropriate level of regulation. Cost-benefit analysis of climate change is designed to determine the level of regulation, but it also encounters difficulties. Cost-benefit analysts must quantify the harm created by carbon emissions, which can be difficult because of uncertainty about the extent of the impact. Economists are also unsure how to take into account the large time-scale of climate change. Thus both approaches have their problems in practice.

There are some possible ways of combining economic analysis and the precautionary principle, but these have not yet been used in practice. In the meantime, the four case studies indicate that decision makers have managed to make reasonably defensible decisions despite the obstacles.

INTRODUCTION

I. WHAT WE KNOW AND WHAT WE DON'T KNOW

ABOUT CLIMATE CHANGE

A. Impacts of Climate Change and Their Potential Severity .. 1663

B. Climate Models and Their Limits

C. Gauging the Extent of Uncertainty ...................................... 1668

II. PRECAUTIONARY APPROACHES

A. The Precautionary Principle and Its Critics.......................... 1671

B. The $2^{\circ} \mathrm{C}$ Target

C. EPA's Formal Finding That Carbon Emissions Endanger

* Sho Sato Professor of Law, University of California, Berkeley. I appreciate the editors' invitation to contribute an article to Washington Law Review and their suggestion of climate change and precaution as a possible topic. 
Human Health and Welfare

D. The Threat of Climate Change to the Survival of Polar

Bears

III. USING COST-BENEFIT ANALYSIS AS THE BASIS FOR CLIMATE POLICY

A. Issues in Calculating the Costs and Benefits of Climate Policy.

1. The Difficulty of Forecasting Economic Harm from Climate Change

2. How Much Should We Discount Future Harms? .... 1692

3. Assessing the Risk of Tipping Point and Catastrophic Outcomes

B. Forecasting the Cost of Climate Change with Integrated Assessment Models

1. The Dynamic Integrated Climate-Economy Model (DICE)

2. The.Climate Framework for Uncertainty, Negotiation and Distribution (FUND)

3. Policy Analysis of the Greenhouse Effect (PAGE).. 1703

4. Summarizing the Models 1704

C. The Government's Estimate of the Cost of Climate Change. 1708

D. Assessing the Application of Cost-Benefit Analysis to Climate Change 1716

IV. LESSONS FROM THE PAST AND DIRECTIONS FOR THE FUTURE

A. Implications of the Case Studies ..................................... 1720

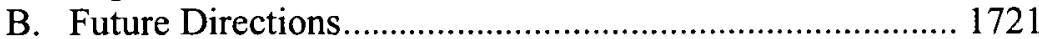

\section{INTRODUCTION "}

As two leading climate scientists have said, "[t]he further we push our Earth outside of its mode of operation of the past millennia, the further we steer it into uncharted waters." Any approach to climate policy must contend with this uncertainty. Ideally, when deciding how much to reduce emissions or whether a particular species is likely to be

1. DAVID ARCHER \& STEFAN RAHMSTORF, THE Climate CRISIS: AN INTRODUCTORY Guide to ClIMATE CHANGE 152 (2010). In particular, the past seven thousand years during which civilization has arisen were unusually stable, so climate change is well outside the circumstances faced by groups within the historical record. See William Nordhaus, The Climate Casino: RisK, UNCERTAINTY, AND ECONOMICS FOR A WARMING WORLD 51 (2013). 
endangered by climate change, policymakers would have a reliable forecast of the precise future impacts of climate change. Although scientists have learned a great deal about climate change, climate science still falls short of this ideal. Yet, decisions must be made in the meantime.

Two rival approaches for dealing with this problem are on the table: the precautionary principle (which is favored by most environmentalists) and cost-benefit analysis (which is favored by most economists). ${ }^{2}$ Many scholars have taken one side or the other on this debate. A few have attempted to reconcile the two. ${ }^{3}$ There have also been examinations of some key decisions in climate policy. But a more systematic, detailed analysis of how the two approaches operate in practice is essential to improving policy analysis. This Article aims to supply that analysis.

Part I of the Article examines the scientific uncertainties that policymakers must confront. The key uncertainties do not involve the existence of climate change or its link with greenhouse gas emissions, both of which are accepted by the overwhelming majority of climate scientists. ${ }^{4}$ Rather they involve its severity. Although we have learned a great deal about the Earth's climate, there are still some significant gaps. Unless or until these gaps are filled by research, they mean that climate policy must build on a scientific foundation that cannot fully predict just how bad climate change will be.

Parts II and III examine the theory and practice of the two contesting approaches to climate policy through use of case studies. As these case studies show, the dispute over the best way to deal with uncertainty is pressing and already confronts government leaders and administrative agencies.

Part II focuses on the precautionary principle as a guide to climate policy. Here, the examples are the international effort to establish the level at which the risks of climate change become unacceptable, the Environmental Protection Agency's (EPA) finding that greenhouse

2. On the conflicts between supporters of these principles, see David M. Driesen, Cost-Benefit Analysis and the Precautionary Principle: Can They Be Reconciled?, 2013 MICH. ST. L. REV. 771, 771-72 (2013). As Driesen puts it, "CBA's fans emphasize quantitative calculation, whilst precaution's advocates stress qualitative judgment. CBA's critics see CBA as an enemy of environmental progress; precaution's detractors see the precautionary principle as a threat to our economy." Id. at 772 .

3. In particular, Driesen argues that the precautionary principle applies to the question of what risks to regulate but not to the stringency of regulation, which can be determined using cost-benefit analysis with precautionary assumptions. Id. at 791, 795, 801. This concept forms part of the new approach discussed in Part $\mathrm{N}$.

4. See, e.g., Richard S.J. Tol, Quantifying the Consensus on Anthropogenic Global Warming in the Literature: A Re-Analysis, 73 ENERGY POL'Y 701 (2014). 
gases warrant regulation under the Clean Air Act, and the Fish and Wildlife Service's (FWS) determination that because of climate change, polar bears are likely to become an endangered species.

Part III analyzes efforts to determine the economic impact of future climate change as a factor in cost-benefit analysis. The main example is the federal government's estimate of the social cost of carbon, but understanding that estimate requires considerable preliminary exploration of climate economics. As we will see, the economic uncertainties amplify the scientific ones, making confident conclusions difficult. But the economic models do confirm the crucial role of three factors in determining the social cost of carbon: the magnitude of climate sensitivity, the size of the discount rate, and the handling of possible catastrophic outcomes.

Part IV then offers some brief conclusions based on these case studies. The precautionary principle seems to work well enough in identifying when climate risks require serious policy responses, but provides less guidance about the extent of the response. On the costbenefit side, uncertainty about the economic impact of climate change remains great, driven largely by disagreements about how heavily to weight harms decades or even centuries in the future and about how to take into account the risks of high climate sensitivity and of catastrophic outcomes.

Some ways of combining use of the precautionary principle and economic analysis have been suggested, but these hybrid approaches have difficulties as well as promise. One fruitful possibility may be to combine these approaches into a two-step process. The first step is to use economic models of climate change, with precautionary assumptions about parameters, to help identify feasible global temperatures that minimize the risk of catastrophic outcomes. The second step is to back out the social cost of carbon based on compliance costs along the most efficient trajectories for reaching this goal. Pending improvements in the decision making process along these or other lines, however, the case studies indicate that decision makers are coping with uncertainty in reasonably defensible ways when making specific policy decisions.

\section{WHAT WE KNOW AND WHAT WE DON'T KNOW ABOUT CLIMATE CHANGE}

One of the key difficulties in formulating climate policy is uncertainty about the severity of climate change. Part I begins by discussing what is known about the impacts of climate change and the dramatic effects that accompany higher levels of global warming. Part I then discusses the reasons why the extent of warming remains subject to uncertainty due to 
limitations in climate models. This uncertainty bedevils efforts to formulate climate policy.

\section{A. Impacts of Climate Change and Their Potential Severity}

The starting point in understanding the impacts of climate change is to survey the changes that have already taken place. And happened they clearly have. According to the most recent report ${ }^{5}$ by the Intergovernmental Panel on Climate Change (IPCC), ${ }^{6}$ "each of the last three decades has been successively warmer at the Earth's surface than any preceding decade since 1850," and "in the Northern Hemisphere, 1983-2012 was likely the warmest 30-year period of the last 1400 years." In other words, the scientists say, the temperature is rising and global warming is already well under way.

This warming has left its mark on the planet. During the past twenty years, the Greenland and Antarctic ice sheets have been shrinking, as have glaciers, Arctic sea ice, and snow cover in the northern hemisphere. ${ }^{8}$ Not surprisingly, given those trends, the rate of sea level increase has accelerated. ${ }^{9}$ Thus, we are already in the midst of sea level rise, and we can expect much more to come.

Although recent years generally rank at the top of the list of the warmest global temperatures, ${ }^{10}$ we can expect considerably more warming in the future, resulting in temperature increases of $2-7^{\circ} \mathrm{C}$ over preindustrial levels (or around $4-12^{\circ} \mathrm{F}$ ). ${ }^{11}$ Temperature change in the

5. Note: In-line citations in the IPCC reports will be deleted in quotations throughout this article without notation to that effect. Also, designations of probability such as "highly unlikely" are generally italicized in the report, but the italics are removed in this Article to avoid distracting the reader.

6. The IPCC is a United Nations body that currently has 195 members, whose mission is to improve scientific understanding of climate change. See Organization, INTERGOVERNMENTAL PANEL ON Climate CHANGE, http://ipcc.ch/organization/organization.shtml (last visited Oct. 21, 2015).

7. Lisa V. Alexander et al., Summary for Policymakers, in INTERgOVERNMENTAL PANEL ON Climate Change, Climate Change 2013: The Physical Science Basis 3, 5 (T.F. Stocker et al. eds., 2013) [hereinafter IPCC 2013 REPORT], available at http://www.climatechange2013.org/images/report/WG1AR5_ALL_FINAL.pdf. The Fifth Assessment Report is commonly referred to as AR5.

8. Id. at 9 .

9. Id. at 11. For a discussion of climate models, their validation, and modeling uncertainties, see generally Daniel A. Farber, Modeling Climate Change and Its Impacts: Law, Policy, and Science, 86 TEX. L. REV. 1655 (2008).

10. ARCHER \& RAHMSTORF, supra note 1 , at 43 .

11. Id. at 129. 
Arctic will be about twice as large. ${ }^{12}$ Even an average global warming of $2^{\circ} \mathrm{C}$ would leave the earth warmer than it has been in millions of years. ${ }^{13}$ But changes in global temperature will not be equally distributed around the planet, just as the planet's current temperature is not evenly distributed. For example, given moderate emissions growth, the predicted global increase by the end of the century is $1.8^{\circ} \mathrm{C}$, but this translates into an average of $2.4^{\circ} \mathrm{C}$ on land and an increase of $4.2^{\circ} \mathrm{C}$ in the Arctic. ${ }^{14}$

Extreme events such as fires, floods, and heat waves will become more widespread. ${ }^{15}$ The IPCC now expresses high confidence that the intensity of extreme weather events will outpace increases in total precipitation, at about $5 \%$ to $10 \%$ for every degree of global temperature increase. ${ }^{16}$ Because the number of severe storms will rise more quickly than the total amount of rain, the average amount of rain in the remaining storms will diminish to compensate for the large amount in the severe storms. In addition, it is "virtually certain" that the number of very hot days will generally increase and very cold days will decrease around the globe.$^{17}$ It is also considered very likely that the Gulf Stream (more technically, the Atlantic Meridional Overturning Circulation or AMOC) will weaken though not collapse during this century. ${ }^{18}$

The effects of a $2^{\circ} \mathrm{C}$ change are bad enough. Impacts are much worse at higher temperatures, such as $4^{\circ} \mathrm{C}$ average warming (or about $7^{\circ} \mathrm{F}$ ), which is a likely eventual outcome if emissions continue to rise. The World Bank considers that scenario to be devastating, with a list of dire consequences including flooding of coastal cities, risks to food security, further drying in arid regions, unprecedented heat waves, and irreversible loss of biodiversity. ${ }^{19}$

\section{Id. at 133 .}

13. Id. at 225 . Unless otherwise indicated, warming estimates in this Article use a baseline of preindustrial temperatures.

14. Matthew Collins et al., Long-Term Climate Change: Projections, Commitments, and Irreversibility, in IPCC 2013 REPORT, supra note 7, at 1029, 1055 (Sylvi Joussaume et al. eds.). These numbers correspond to the IPCC's RCP4.5 scenario. The IPCC is an international organization under the auspices of the United Nations that is charged with giving policymakers a reliable presentation of the science relating to climate change.

15. ARCHER \& RAHMSTORF, supra note 1, at 174; see HeIDI Cullen, THE WeATHER OF THE Future: Heat Waves, Extreme Storms, and Other Scenes from a Climate-Changed PlanET (2010).

16. Olivier Boucher et al., Clouds and Aerosols, in IPCC 2013 REPORT, supra note 7, at 571, 626-27 (Sanro Fuzzi et al. eds.).

17. Collins et al., supra note 14 , at 1031.

18. Id. at 1033 .

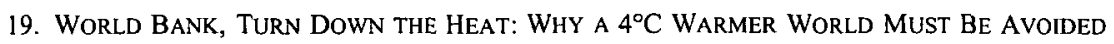


What the future holds is uncertain, in part because it is not clear how much carbon humankind will continue to pump into the atmosphere, or at what rate. To model possible scenarios, the IPCC has created several "representative concentration pathways" (RCPs), which represent a range of possible climate policies and their concomitant impacts on the rate and quantity of carbon emissions. ${ }^{20}$ In one of the scenarios (RCP2.6), stringent mitigation measures result in atmospheric concentrations peaking and then declining by 2100 ; another scenario assumes very high emissions (RCP8.5), while two intermediate scenarios (RCP4.5 and RCP6.0) assume that emissions are eventually stabilized. ${ }^{21}$

The difference between these scenarios is substantial. The RCP8.5 scenario results in $4.5^{\circ} \mathrm{C}$ of warming by 2100 , while at the other extreme the RCP2.6 scenario leads to less than $2^{\circ} \mathrm{C}$ of warming. ${ }^{22}$ Thus, they correspond roughly to the difference between the $2^{\circ} \mathrm{C}$ world discussed above and the $4^{\circ} \mathrm{C}$ world. The $4^{\circ} \mathrm{C}$ world is much more severe. But the contrast is actually potentially much greater, because those estimates cut off at the year 2100 . If we go out another two centuries to 2300 , the low

xiii (2012), available at http:/www-wds.worldbank.org/extemal/default/WDSContentServer/ WDSP/IB/2015/07/17/090224b0828c33e7/1_0/Rendered/PDF/Turn0down0the00orld0must0be0avo ided.pdf. The threat to biodiversity is not terribly surprising, because plants and animals are generally no more immune from heat waves, droughts, cyclones, and flooding than are humans, crops, and domesticated animals. Because of the rapid pace of climate change, "[m]any species will be unable to disperse rapidly enough to track the changing climate and remain within their 'climate envelope' of temperature and precipitation." RICHARD PRIMACK, ESSENTIALS OF CONSERVATION BIOLOGY 208 (5th ed. 2010).

20. For simplicity, this Article focuses on carbon dioxide $\left(\mathrm{CO}_{2}\right)$, and leaves other greenhouse gases aside.

21 . Collins et al., supra note 14 , at 1058 . The numerical designations, such as 2.6 , refer to the additional warming in 2100 relative to 1750 . Therefore, RCP2.6 means that radiative forcing (the equivalent of the extra heating in terms of additional solar energy) in that year is 2.6 watts per square meter greater than $1750 . \mathrm{Id}$. (Watts are a measure of power, which is familiar to most people in the form of the wattage of light bulbs or kilowatts - thousands of watts - of power used on a consumer electrical bill.) One watt per square meter translates, as a matter of simple arithmetic, into 100 watts per 10 -by-10 square meters. So we can imagine the total amount of heat by imagining that the earth was covered with a web of old-fashioned 100 -watt bulbs, each of them ten meters from the nearest bulb. The area of the earth is approximately 500 million square kilometers, Jerry Coffey, Surface Area of the Earth, UNIVERSE TODAY (Feb. 18, 2009), http:/www.universetoday.com/ 25756/surface-area-of-the-earth/, and each square kilometer contains 10,000 10-by-10 square meters as a matter of more simple arithmetic. Thus, some further arithmetic shows that it would take 50 trillion 100-watt bulbs to deliver 1 watt per square meter of radiative forcing. Although the heating from any one bulb is not large, it is not surprising that the heat from 50 trillion bulbs (or a multiple thereof) might affect the planet, especially if continued over many years.

22. See Alexander et al., supra note 7, at 28 fig.SPM.10. There are substantial error ranges around this estimate. For instance, the high emissions scenario could cause temperature increases of between about $2.25^{\circ} \mathrm{C}$ and $4.5^{\circ} \mathrm{C}$ by 2100 . Id . at 1033 (see error bars on side of graph). 
emissions scenario still shows an increase a bit over $2^{\circ} \mathrm{C}$, but the high emissions scenario now shows an $8^{\circ} \mathrm{C}$ increase. ${ }^{23}$ Imagine adding an additional $14^{\circ} \mathrm{C}$ or $15^{\circ} \mathrm{C}$ to this year's hottest summer day.

As the use of these multiple scenarios indicates, there are some unknowns about the trajectory of future climate change. How fast the world will warm and the severity of the effects in different locales remains unclear. The next section considers those uncertainties in more depth.

\section{B. Climate Models and Their Limits}

The problem is that despite very sophisticated and extensive efforts to improve climate modeling, the remaining area of uncertainty is substantial. There is seemingly no significant uncertainty about the fact the earth has been warming: The IPCC considers the evidence for warming unequivocal, marked by many observed changes in earth and biological systems. ${ }^{24}$ But the details are subject to various shades of uncertainty, which the IPCC has meticulously chronicled using its formal terminology. For instance, there is "very high confidence" that models can reproduce historical temperature trends, but as of 2013 there was only "medium confidence" that apparent deviations from model predictions from 1998-2012 were due to natural variability. ${ }^{25}$

Climate models are enormously complex and require the use of supercomputers to run. ${ }^{26}$ Even so, as the IPCC has explained, ${ }^{27}$ compromises must be made to allow even the supercomputers to manage the models. ${ }^{28}$ The earth's surface (and the atmosphere above and ocean below) is represented through a grid; the size of the grid determines the scale at which the model can make predictions and also affects its accuracy. ${ }^{29}$ The temporal resolution is also limited because it is not practical to run the model to simulate changes every second over the course of decades or even centuries. Dealing with these limitations requires the use of approximations to deal with smaller scale

23. Collins et al., supra note 14, at 1054 fig. 12.5 (based on the solid lines, which are mean model ensemble estimates).

24. Alexander et al., supra note 7, at 4.

25. Gregory Flato et al., Evaluation of Climate Models, in IPCC 2013 REPORT, supra note 7, at 741,743 (G. Flato et al. eds.).

26. Id. at 749 .

27. Id.

28. See Farber, supra note 9, at 1658-61.

29. Id. 
phenomenon such as cloud behavior. ${ }^{30}$ Modelers must also make decisions about which of the many processes that shape the weather should be included or left out. ${ }^{31}$ Models are also tuned by setting some parameters based on historic data; obviously, the model's ability to "predict" the same historical data for those same parameters does not provide any test of its accuracy, so other tests must be used. ${ }^{32}$

Climate scientists have devoted enormous effort to assessing models, such as checking their ability to reproduce historic data trends (on parameters other than the ones used for tuning). ${ }^{33}$ Scientists have also developed quantitative metrics for model performance. ${ }^{34}$ Models have clearly improved over time in a number of dimensions-for example, they are better able to predict changes in Arctic sea ice. ${ }^{35}$

Despite all these efforts, there is still considerable uncertainty about the severity of future climate change for given emissions scenario. The amount of temperature changes depends not only on the amount of additional greenhouse gases in the scenario, but also on just how sensitive the climate is to greenhouse gases. This sensitivity is measured by determining how the climate would respond to a doubling of atmospheric $\mathrm{CO}_{2}{ }^{36}$ Despite model improvements, the likely range of sensitivities continues to be $2.1-4.4^{\circ} \mathrm{C},{ }^{37}$ thus differing by around a factor of two. ${ }^{38}$ As we saw previously, the global impacts are also likely to be much more severe at the higher temperature.

The range in estimates is due to a number of differences between models regarding factors such as humidity, sea ice and snow cover, cloud feedbacks, and so forth. ${ }^{39}$ The primary factor that seems to drive the differences in sensitivity estimates between models is projections relating to clouds, which can reflect sunlight back into space during the day but also keep heat from escaping at night. ${ }^{40}$ Overall, climate models

30. Id.

31. Flato et al., supra note 25 , at 743 .

32. Id. at 750 .

33. Id. at $760-66$.

34. Id. at $766-67$.

35. Gunnar Myhre \& Drew Shindell, Anthropogenic and Natural Radiative Forcing, in IPCC 2013 REPORT, supra note 7, at 659, 708 (Gunnar Myhre et al. eds.).

36. Flato et al., supra note 25 , at 817.

37. The likely range has been basically the same over the past several decades. See GERNOT WAgner \& MaRTin L. WeItZman, Climate Shock: THE ECONomic CONSEQuences of a HOTTER PLANET 13 (2015).

38. Flato et al., supra note 25 , at 817.

39. Id. at 819-20.

40. Id. at 821 . 
do seem to be improving, for instance in their ability to predict the frequency of extreme weather" (though there is still only "medium evidence and high agreement" that the models have improved in this respect). ${ }^{42}$

Even when models do agree, there are residual grounds for uncertainty. A model is only as good as the data it uses. Similar data is fed into all of the models, so they will all be off if there are errors in the data ${ }^{43}$ In addition, because scientists share a common understanding of how climate works and use similar methods of programming, the models might share a common error in the way they represent climate processes. ${ }^{44}$ There do not seem to be major missing factors in the models, however, at least in terms of explaining overall twentieth century warming trends. ${ }^{45}$ Nevertheless, we know that other factors are relevant and imperfectly modeled for future trends and regional impacts (as shown, for example, by the disagreements between models over the expected future degree of warming in various scenarios). ${ }^{46}$

\section{Gauging the Extent of Uncertainty}

Uncertainty is an abiding concern of climate scientists, and the IPCC has evolved a specialized vocabulary for specifying levels of uncertainty. ${ }^{47}$ The reader may find the following table helpful in interpreting statements from the IPCC's reports ${ }^{48}$ :

41. Nathaniel L. Bindoff et al., Detection and Attribution of Climate Change: From Global to Regional, in IPCC 2013 REPORT, supra note 7, at 867, 907 (N.L. Bindoff et al. eds.).

42. Flato et al., supra note 25 , at 809.

43. Myles Allen et al., Scientific Challenges in the Attribution of Harm to Human Influences on Climate, 155 U. PA. L. REV. 1353, 1361 (2007).

44. Id. ("There is considerable debate over the extent to which currently available models span the range of plausible real-world responses.").

45. Id. at 1375 .

46. Gerald A. Meehl \& Thomas F. Stocker, Global Climate Projections, in Intergovernmental Panel on Climate Change, Climate Change 2007: The Physical SCIENCE BASIS 748, 797 (2007), available at http:/www.ipcc.ch/pdf/ assessment-report/ar4/wg1/ar4-wgl-chapter 10.pdf. As the IPCC's review of the literature explains:

Uncertainty in predictions of anthropogenic climate change arises at all stages of the modeling process .... The specification of future emissions of greenhouse gases, aerosols, and their precursors is uncertain. It is then necessary to convert these emissions into concentrations [of greenhouse gases], calculate the associated forcing [the direct temperature effect] and predict the response of climate system variables such as surface temperature and precipitation. At each step, uncertainty in the true signal of climate change is introduced both by errors in the representation of Earth system processes in models and by internal climate variability.

Id. (citations omitted).

47. Alexander et al., supra note 7, at 4 .

48. Thomas F. Stocker et al., Technical Summary, in IPCC 2013 REPORT, supra note 7, at 33, 36 


\begin{tabular}{|l|l|}
\hline \multicolumn{2}{|c|}{ Table 1-IPCC Uncertainty Designations } \\
\hline Term & Likelihood \\
\hline Virtually Certain & Over $99 \%$ \\
\hline Extremely Likely & Over $95 \%$ \\
\hline Very Likely & Over $90 \%$ \\
\hline Likely & Between $66-90 \%$ \\
\hline More Likely Than Not & Over $50 \%$ \\
\hline As Likely as Not & Between 33-66\% \\
\hline Unlikely & Under 33\% \\
\hline Very Unlikely & Under $10 \%$ \\
\hline
\end{tabular}

The IPCC also has a set of terms corresponding to subjective levels of confidence by experts, with modifiers including "very low," "low," "medium," "high," and "very high."49 Neither lawyers nor economists have evolved anything similar, and the efforts of these scientists to provide systemized designations of uncertainty is one indication of their careful attention to the limits of the science. The IPCC terminology often feels clumsy, but it reflects a laudable effort to indicate what conclusions are uncertain and the magnitude of the uncertainty.

Some efforts have been made to quantify uncertainty based on various other lines of evidence. ${ }^{50}$ Computational experiments have been performed to quantify uncertainty about how models respond to external inputs such as changes in solar intensity, including evidence about how uncertainties concerning processes that cannot be modeled fully translate into the uncertainty in climate change projections. ${ }^{51}$ This is accomplished, basically, by running models hundreds of times with different parameters to see how the results differ. ${ }^{52}$

Unfortunately, there is no completely satisfactory way of translating these results into a formal probability distribution. ${ }^{53}$ If we assume that all current models are equally likely and that they exhaust the possibilities, we can get a probability distribution, but these are somewhat heroic

(Sylvie Joussaume et al. eds.).

49. Id. at $35 \mathrm{n} .1$.

50. Meehl \& Stocker, supra note 46 , at 754.

51. Id.

52. Id.

53. Id. at 799 . 
assumptions. ${ }^{54}$ Consequently, it may be a mistake to assume that we can derive firm probability estimates by comparing the outputs of current models. ${ }^{55}$

One way of comparing the models is to focus on their estimates of climate sensitivity, which is the long-term temperature increase that would be caused by permanently doubling $\mathrm{CO}_{2}$ levels over the preindustrial level. Some studies show that it is difficult to represent past climate and variability with sensitivities below $2^{\circ} \mathrm{C}$, and while sensitivities around $5^{\circ} \mathrm{C}$ are possible, the best fit with observations seems to involve a climate sensitivity of $3-4^{\circ} \mathrm{C} .{ }^{56} \mathrm{Keep}$ in mind that the sensitivity is a measure of the responsiveness of the climate system; actual climate change could be higher if $\mathrm{CO}_{2}$ levels go beyond twice the preindustrial level. The world could well go beyond doubling of preindustrial carbon levels, resulting in temperature increases that are proportionally more than the climate sensitivity. In addition, this is an equilibrium temperature that would not be reached for some time until the climate system fully adjusts to the higher carbon level.

The IPCC's current view is that sensitivity is "likely in the range $1.5^{\circ} \mathrm{C}$ to $4.5^{\circ} \mathrm{C}$ with high confidence, extremely unlikely less than $1{ }^{\circ} \mathrm{C}$ (high confidence), and very unlikely greater than $6^{\circ} \mathrm{C}$ (medium confidence). ${ }^{, 57}$ Translating this out of IPCC-talk using the table above, we get the following information:

\begin{tabular}{|l|l|l|}
\hline \multicolumn{3}{|c|}{ Table 2-Estimates of Climate Sensitivity } \\
\hline Sensitivity & $\begin{array}{l}\text { Estimated Probability } \\
\text { of Climate Sensitivity } \\
\text { in This Range }\end{array}$ & $\begin{array}{l}\text { Level of Confidence } \\
\text { in Probability } \\
\text { Estimate }\end{array}$ \\
\hline Below $1^{\circ} \mathrm{C}$ & Under $5 \%$ & High Confidence \\
\hline 1.5 to $4.5^{\circ} \mathrm{C}$ & Over $90 \%$ & High Confidence \\
\hline Above $6^{\circ} \mathrm{C}$ & Under $10 \%$ & Medium Confidence \\
\hline
\end{tabular}

The differences between the climate sensitivities even within the middle range are substantial - as Part I.A explained, there are great differences between the $2^{\circ} \mathrm{C}$ world and the $4^{\circ} \mathrm{C}$ one. But the estimates

\footnotetext{
54. Id.

55. As one climate scientist explains, "[w]hile ensemble projections carried out to date give a wide range of responses, they do not sample all possible sources of modeling uncertainty .... More generally, the set of available models may share fundamental inadequacies, the effects of which cannot be quantified." Id. at 805 .
}

56. Id. at 821 .

57. Collins et al., supra note 14, at 1033. 
leave a worrisome possibility that sensitivity is even higher, with even more dire consequences than $4^{\circ} \mathrm{C}$.

Moreover, the likelihood of an increase of as much as $6^{\circ} \mathrm{C}$ is not inconsiderable, perhaps as high as one out of ten, given the combination of possible high climate sensitivity with high emissions scenarios. ${ }^{58}$ The scale of the resulting changes should not be underestimated: When the world was $2.5^{\circ} \mathrm{C}$ warmer than the present, in the early Paleolithic, camels roamed Canada. ${ }^{59}$

For any given level of physical impact from climate change, the human impact will turn on other factors, such as the human ability to adapt to climate change. The next Part of the Article focuses on one widespread approach to making policy in the face of these and other uncertainties.

\section{PRECAUTIONARY APPROACHES}

Uncertainty is the focus of one accepted approach to environmental policy, the precautionary principle. This section considers how that approach has been used. The section begins with an explanation of the precautionary principle and an overview of the vigorous debate over its validity. The section then turns to three case studies where the precautionary principle was applied to climate change: the international community's key policy decision, the EPA's key regulatory decision, and the FWS's determination of the impacts of climate change on biodiversity.

\section{A. The Precautionary Principle and Its Critics}

In its most general sense, the precautionary principle advises that lack of certainty is not a justification for inaction in the face of possible risks. ${ }^{60}$ The argument is made all too often that no action should be taken

58. Using the IPCC's statements about climate sensitivity and fitting a lognormal curve, Wagner and Weitzman find about a $10 \%$ chance of temperatures eventually crossing this threshold. WAGNER \& WEITZMAN, supra note 37 , at $50-58,180-81$. Note that the $10 \%$ figure is for an eventual $\mathrm{CO}_{2}$ concentration of 700 parts per million (ppm), which they characterize as basically business-as-usual with the deduction of climate reductions promised as of 2013. Id. at 55. The concentration is currently around $400 \mathrm{ppm}$, Earth's $\mathrm{CO}_{2}$ Home Page, $\mathrm{CO}_{2}$ Now.orG, http://co2now.org/current-co2/co2-now/ (last visited Oct. 21, 2015), while the preindustrial level was about 280 so that the doubled amount is 560 . The preindustrial level of $280 \mathrm{ppm}$ is referenced in NORDHAUS, supra note 1 , at 4.

59. WAGNER \& WEITZMAN, supra note 37 , at 10,163 . It is important to note this temperature increase would not necessarily take place during this century.

60. As Nash points out, "the precautionary principle calls for the use of caution in making 
because of scientific uncertainty about whether a risk exists or its size. Uncertainty is clearly a factor in deciding how to respond, but it is irrational to completely ignore the possibility of a downside risk simply because it has not been proved beyond a reasonable doubt. The precautionary principle is a reminder that the reasonable person does not wait for certainty to adopt safety precautions. Clearly, if society waits to prohibit hunting members of an endangered species until extinction is a certainty, it will be too late to save the species.

Critics often advocate the precautionary principle as an alternative to cost-benefit analysis, based on the idea that "we should pay attention to early warnings of serious hazards, rather than wait for final proof and precise quantification of the expected impacts." ${ }^{, 61}$ In such situations, they argue, we should "tilt toward overinvestment in protecting ourselves and our descendants." ${ }^{, 62}$ The precautionary principle has been explained on the basis of risk aversion or skepticism about the environment's ability to tolerate damage. ${ }^{63}$ Although the precautionary principle is not explicitly featured in American environmental law, it is easy to find examples of statutes with parallel features ${ }^{64}$ and the United States has joined treaties requiring precautionary environmental protection. ${ }^{65}$

The best-known statement of the precautionary principle is found in the Rio Declaration. It states that "to protect the environment, the

regulatory decisions when risk or uncertainty is present." Jonathan Remy Nash, Standing and the Precautionary Principle, 108 COLUM. L. REV. 494, 500 (2008).

61. Frank ackerman \& Lisa heinzerling, Priceless: ON KNOWING the Price of EVERYTHING AND THE VALUE OF NOTHING 225 (2004).

62. Id. at 227. In his Article, Kysar suggests that the precautionary principle is especially useful in situations where outcomes are poorly defined. Douglas A. Kysar, It Might Have Been: Risk, Precaution, and Opportunity Costs, 22 J. LAND USE \& ENVTL. L. 1, 14 (2006). He views this observation as particularly relevant to climate change:

Realistic but unquantifiable threats of catastrophic loss present an additional case in which heuristic decision procedures [such as the precautionary principle] may prove more pragmatically sensible than deliberate cost-benefit optimization. With regard to climate change, for instance, future generations may reflect with marvel on our present day attempts to meticulously calculate the costs and benefits of greenhouse policies.

Id. at 25 .

63. See Daniel Farber, Eco-Pragmatism: Making Sensible Environmental Decisions in AN UNCERTAIN WORLD 170 (1999).

64. Two cases that helped cement this principle are Reserve Mining Co. v. EPA, 514 F.2d 492 (8th Cir. 1975) (en banc) and Ethyl Corp. v. EPA, 541 F.2d 1 (D.C. Cir. 1976) (en banc). The endangerment requirement discussed in Part II.B is a prime example of a mandate incorporating precaution. For examples of statutes that go even further and shift the burden of proof on safety, see Noah M. Sachs, Rescuing the Strong Precautionary Principle from Its Critics, 2011 U. ILL. L. REV. $1285,1307-11$

65. See Driesen, supra note 2 , at 813 . 
precautionary approach shall be widely applied by States according to their capabilities," and that given "threats of serious or irreversible damage, lack of full scientific certainty shall not be used as a reason for postponing cost-effective measures to prevent environmental degradation. ${ }^{, 66}$ To unpack this standard a bit, it calls for cost-effective measures to deal with a threat of serious or irreversible harm; uncertainty does not preclude action but the degree of uncertainty might be relevant in determining what measures should be considered costeffective. A weather forecast with a high chance of rain and possible thunderstorms does not justify taking refuge in the basement but it does justify carrying an umbrella.

Advocates of the precautionary principle point to evidence of broad international acceptance. ${ }^{67}$ Since the Rio Declaration, many countries and courts have embraced the precautionary principle, perhaps to the point that it is now part of customary international law. ${ }^{68}$ The precautionary principle also appears in international conventions on ozone, global climate, and biodiversity. ${ }^{69}$ The precautionary principle served as the basis for the European Union's effort to regulate the use of

66. United Nations Conference on Environment and Development, Rio de Janeiro, Braz., June 314, 1992, Rio Declaration on Environment and Development, U.N. Doc. No. A/CONF.151/26/Rev.1 (Vol. I), Annex I, princ. 15 (Aug. 12, 1992).

67. Nash, supra note 60 , at 499 . Additional information about acceptance of the precautionary principle can be found in Jonathan $\mathrm{B}$. Wiener, Precaution and Climate Change, in OXFORD HANDBOOK OF INTERNATIONAL Climate Change LAW 1, 4 (Cinnamon Carlame et al. eds., 2014). It should be noted, however, that application of the precautionary principle may be more nuanced and involve balancing of precaution against other considerations. See Gregory N. Mandell \& James Thuo Gathii, Cost-Benefit Analysis Versus the Precautionary Principle: Beyond Cass Sunstein's Laws of Fear, 2006 U. ILL. L. REV. 1037. On the other hand, some precautionary stances are oblivious to costs, such as the view that we should stabilize greenhouse gas concentrations "at a level that is hoped to be sufficiently low to eliminate the possibility of truly disastrous climate change scenarios . . . whatever the cost." Kysar, supra note 62, at 25 (emphasis in original).

68. See Responsibilities and Obligations of States Sponsoring Persons and Entities with Respect to Activities in the Area, Case No. 17, Advisory Opinion of Feb. 1, 2011, 2011 ITLOS Rep. 10, I 135. The tribunal states:

The Chamber observes that the precautionary approach has been incorporated into a growing number of international treaties and other instruments, many of which reflect the formulation of Principle 15 of the Rio Declaration. In the view of the Chamber, this has initiated a trend towards making this approach part of customary international law. This trend is clearly reinforced by the inclusion of the precautionary approach in the Regulations and in the "standard clause" contained in Annex 4, section 5.1, of the Sulphides Regulations. So does the following statement in paragraph 164 of the ICJ Judgment in Pulp Mills on the River Uruguay that "a precautionary approach may be relevant in the interpretation and application of the provisions of the Statute" (i.e., the environmental bilateral treaty whose interpretation was the main bone of contention between the parties).

Id.

69. David Hunter et al., International EnVironmental LaW and Policy 410 (2d ed. 2002). 
genetically modified organisms (GMOs) in foods, with concerns about as yet unproven adverse effects on human health as the dominant concern rather than the balance between possible risks and the benefits offered by GMOs. ${ }^{70}$ At the national level, it has been adopted by Germany as a guide to environmental policy and has been invoked by courts in Canada, Pakistan, and India. ${ }^{71}$

Despite its broad international acceptance, the precautionary principle is controversial. ${ }^{72}$ There seem to be two main criticisms. ${ }^{73}$ The first is the precautionary principle's soft edges. ${ }^{74}$ For years, critics have complained about the lack of consensus regarding what it means and when it applies. ${ }^{75}$ In some formulations, the precautionary principle is seemingly a mandate to halt activities when a sufficient level of risk appears, regardless of cost, whereas in others it merely creates a presumption against activities potentially harmful to the environment, placing the burden of proof on the advocates of those activities. ${ }^{76}$ But none of these formulations is precise, and some observers view the precautionary

70. David G. Owen, Bending Nature, Bending Law, 62 FLA. L. REV. 569, 575 (2010); HuNTER ET AL., supra note 69 , at 407 .

71. HUNTER ET AL., supra note 69, at 410-11. On the Canadian experience, see Juli Abouchar, The Precautionary Principle in Canada: The First Decade, 32 ENVTL. L. REP. 11,407 (2002).

72. For a recent update on the debate, see Fritz Allhoff, Risk, Precaution, and Emerging Technologies, 3 STUD. ETHICS L. \& TECH. 1 (2009). Allhoff suggests that "precaution supplements cost-benefit analysis given uncertainty." Id. at 23 (emphasis in original).

73. A third criticism connects the precautionary principle with defects in human cognition. Sunstein has argued that when the precautionary principle "seems to offer guidance," it is "often because of the operation of probability neglect," meaning the cognitive incapacity of individuals to attend to the relevant risks. Cass R. Sunstein, Probability Neglect: Emotions, Worst Cases, and Law, 112 Yale L.J. 61, 94 (2002) [hereinafter Sunstein, Probability Neglect]. Sunstein further elaborated his critique in Cass R. Sunstein, Beyond the Precautionary Principle, 151 U. PA. L. REV. 1003 (2003) [hereinafter Sunstein, Precautionary]. Defenders of the precautionary principle argue, however, that the principle can actually counter defects in the ways people process probability information. David Dana, The Contextual Rationality of the Precautionary Principle, 35 QUEEN'S L.J. 67, 74-80 (2009). For instance, climate change could be an example of an area where people will "irrationally over-weigh the costs of regulating and irrationally under-weigh the costs of regulatory inaction." Id. at 79 . Invoking the precautionary principle might rebalance the policy discourse on this issue and could counteract this tendency. Id. at 81.

74. See Edward A. Parson, The Big One: A Review of Richard Posner's Catastrophe: Risk and Response, 45 J. ECON. LITERATURE 147, 152 (2007) (commenting on the precautionary principle's "squishiness").

75. See Christopher D. Stone, Is There a Precautionary Principle?, 31 ENVTL. L. REP. 10,790, 10,791 (2001). Similarly, Wiener observes that common versions of the precautionary principle do not specify the levels of risk or harm needed to trigger the principle with any specificity, how early anticipatory action should be taken, or how strong the response should be. Wiener, supra note 67 , at 4. Given this lack of specificity, Wiener thinks it appropriate to refer to precaution as a "stance" or "posture" involving a continuum of possible situations and response, Id.

76. Stone, supra note 75 , at 10,791 . 
principle as little more than general advice to be careful. ${ }^{77}$ An admonition to exercise care is not necessarily undesirable, but it falls short of the guidance we would hope that the law would give decision makers.

The vagueness criticism has prompted various attempts to give the precautionary principle greater content with reference to avoiding irreversible actions, keeping options open, and providing insurance against dangerous risks. ${ }^{78}$ Alternatively, some supporters argue that the principle requires a kind of case-by-case, common law development. ${ }^{79}$ Efforts have also been made to sharpen the precautionary principle in three settings: The first, which has been called "the heartland of the precautionary principle," involves situations where "the risk cannot be effectively assessed or reliably cabined-i.e., settings in which there is uncertainty rather than simply risk." 80 An example might be the possibility of a future tipping point in climate change, which at this point cannot be estimated reliably. The second setting is where "a failure to regulate may result in irreversible harm," so that "an investment in regulation may be justified by a desire to retain flexibility by avoiding irreversible results." ${ }^{, 81}$ The clearest example is protecting an endangered species, because once it has occurred it will be impossible to reverse. The final setting is where harm would be catastrophic. ${ }^{82}$ Again, a major tipping point could be an example.

Use of precaution in the final category on this list (catastrophic risks) actually has some support even from Cass Sunstein, a leading critic of the precautionary principle. ${ }^{83}$ Sunstein proposes a number of different versions of the catastrophic risk precautionary principle, in increasing order of stringency. The first requires only that regulators take into account even highly unlikely catastrophes. ${ }^{84}$ Another version "asks for a degree of risk aversion, on the theory that people do, and sometimes

77. Id. at 10,792 .

78. See, e.g., Stephen Charest, Bayesian Approaches to the Precautionary Principle, 12 DUKE ENVTL. L. \& POL'Y F. 265 (2002); Christian Gollier et al., Scientific Progress and Irreversibility: An Economic Interpretation of the 'Precautionary Principle,' 75 J. PUB. ECON. 229 (2000); W. David Montgomery \& Anne E. Smith, Global Climate Change and the Precautionary Principle, 6 HuM. \& ECOLOGICAL RISK ASSESSMENT 399 (2000); Stone, supra note 75.

79. See Stephen Toulmin, The Case for Cosmic Prudence, 56 TENN. L. REV. 29 (1988).

80. Nash, supra note 60 , at $502-03$.

81. Id.

82. Id.

83. Cass R. Sunstein, The Catastrophic Harm Precautionary Principle, 6 IsSUES LEGAL SCHOLARSHIP 1 (2007).

84. Id. at 28 . 
should, purchase insurance against the worst kinds of harm." ${ }^{85}$ Hence, he said, "a margin of safety is part of the Catastrophic Harm Precautionary Principle - with the degree of the margin depending on the costs of purchasing it. ${ }^{" 86}$ This suggestion essentially says that society should be willing to pay something as "insurance" against possible catastrophe. Finally, Sunstein suggested, "it sometimes makes sense to adopt a still more aggressive form of the Catastrophic Harm Precautionary Principle," one "selecting the worst-case scenario and attempting to eliminate it." ${ }^{" 87}$ Although Sunstein himself might not agree, this is a possible perspective on potentially catastrophic tipping points and climate change. In any event, as Sunstein's effort illustrates, it may be possible to sufficiently clarify the areas of application for the precautionary principle to make the principle a workable guide to decisions.

A second, more substantive criticism of the principle is that risk is inevitably two-sided because government intervention creates risks of its own. ${ }^{88}$ If the possible effects of regulating one risk include additional risks to health and environment, then the precautionary principle seems to turn against itself, suggesting that we should not proceed with environmental regulations until we can pin down their effects. If the precautionary principle implies that it is better to overregulate than under-regulate new technologies, that approach might itself violate the precautionary principle by risking greater harm to the public. ${ }^{89}$ For example, Sunstein says, the precautionary principle might seem to call for stringent regulation of genetic engineering because of possible ecological risks, but the regulation itself would also create risks because "genetic engineering holds out a prospect of producing ecological and health benefits." 90 Thus, he says, "[t]he precautionary principle would seem both to require and to forbid stringent regulation of genetic

\section{Id.}

86. Id.

87. Id. Sunstein added a caution, however, that "maximin is not generally a sensible strategy in the environmental context or elsewhere" because it makes no sense when risks can actually be quantified even roughly and is not attractive when the worst-case scenario is only mildly bad or when the cure inflicts "serious losses of its own." Id. at 28-29 (emphasis in original).

88. See Jonathan H. Adler, More Sorry than Safe: Assessing the Precautionary Principle and the Proposed International Biosafety Protocol, 35 TEX. INT'L L.J. 173, 194 (2000); Frank B. Cross, Paradoxical Perils of the Precautionary Principle, 53 WASH. \& LEE L. REv. 851, 872 (1996).

89. See Adler, supra note 88 , at $195-98$.

90. Sunstein, Probability Neglect, supra note 73 , at 93 . The version of precaution discussed in this Article is more forgiving toward technologies with high upside potential and hence seems less vulnerable to this criticism. 
engineering." Sunstein argues that the "same can be said for many activities and processes, such as nuclear power and nontherapeutic cloning, simply because risks are on all sides of the situation. ${ }^{, 92}$

Sunstein's critique seems overstated. In some situations, risks on one side may well be clearly more severe than on the other, or it simply may be impractical to consider all possible tradeoffs. ${ }^{93}$ Moreover, the precautionary principle could sometimes help serve other purposes, such as creating information-forcing incentives for industry to investigate and dispel possible risks. ${ }^{94}$

But there may also be situations where Sunstein is right. One such situation may be the use of geo-engineering to address climate change. The IPCC has investigated the potential impacts of solar radiation management (SRM) methods, such as sending aerosols into the stratosphere to reduce the amount of energy reaching the surface of the earth. ${ }^{95}$ There is limited literature on this emerging set of technologies. ${ }^{96}$ According to the IPCC, "a geoengineered climate with SRM and high atmosphere $\mathrm{CO}_{2}$ levels would generally be closer to twentieth century climate than a future climate with elevated $\mathrm{CO}_{2}$ and no SRM., ${ }^{, 97}$ In particular, "SRM in concert with aggressive $\mathrm{CO}_{2}$ mitigation might conceivably help avoid transitions across climate thresholds or tipping points that would be unavoidable otherwise. ${ }^{, 98}$ But there are also possible side effects. ${ }^{99}$ Worse, once begun, it might be impossible to stop

91. Id.

92. Id. These forms of geo-engineering would not address the important problem of ocean acidification. NORDHAUS, supra note 1 , at 113.

93. See Sachs, supra note 64 , at $1316-25$.

94. Sunstein, Probability Neglect, supra note 73, at 93; see also Wiener, supra note 67, at 6-7.

95. Boucher et al., supra note 16 , at 627 . Several other techniques have also been studied, including cloud brightening, whitening the earth's surface in various ways, or thinning cirnus clouds. Id. at 628 . One limitation on existing studies is that they unrealistically posit a uniform decrease in total solar radiation, as if space reflectors were used to deflect incoming light. Id. at 629 . Another approach to geo-engineering is to remove $\mathrm{CO}_{2}$ from the atmosphere. One major uncertainty relates to the permanence of this method, because the effect could be to pull more $\mathrm{CO}_{2}$ out of the ocean and back into the atmosphere. Id. at 633 . There are probably limits to scaling up these techniques. Id. There could also be side effects, some of them counter-intuitive: "[A]fforestation in seasonally snow-covered boreal regions could in fact accelerate global warming." Id. The reason, seemingly, is that trees are darker than snow and therefore reflect less heat back into space.

96. Id. at 635 (noting that the study of these issues is "still in its infancy").

97. Id. at 634 .

98. Id. at 635 .

99. Studies show, for instance, that the aerosol method could produce a significant cooling effect, but some studies show that there might be side-effects such as increased ozone loss with a consequent increase in the amount of ultraviolet radiation on the earth's surface. Id. at 628. In terms of temperature, there is generally cooling in the tropics and warming elsewhere (compared to the 
engaging in SRM: Given that high $\mathrm{CO}_{2}$ levels will last for over a thousand years, it would be necessary to continue SRM for centuries. ${ }^{100}$ If SRM faltered, it could take only twenty years or less to undo its benefits completely, abruptly returning the world to an advanced point on the global warming pathway. ${ }^{101}$ Despite these uncertainties and clear risks, however, geoengineering needs to be compared with the alternatives, which could also include disastrous climate changes unless appropriate mitigation measures are adopted (which might not happen). ${ }^{102}$ Given the clear risks on both sides, an attitude of precaution may not point in any clear direction.

Yet, although Sunstein's critique may hold true in the case of geoengineering, it is by no means evident that this is a common situation. Much regulated conduct, like carbon emissions, has no clear benefit, and the only downside of regulation is cost. While cost is not an irrelevant factor, it is a known quantity, not a source of uncertain harms.

We can expect the debate over the precautionary principle to continue, but it may be possible to find consensus on narrower ground. As we have seen, Sunstein is a long-time critic of the precautionary principle. Even so, he has recognized that it might have pragmatic value as a spur for addressing neglected risks and as "a plea for a kind of regulatory insurance." ${ }^{103}$ In any event, it is an approach commonly used around the world. The remainder of this part of the Article examines precautionary responses to climate risks in both the international and domestic contexts.

\section{B. The $2^{\circ} \mathrm{C}$ Target}

The precautionary principle is invoked by the United Nations Framework Convention on Climate Change (UNFCCC) ${ }^{104}$ in two places. Article 3(3) states that States "should take precautionary measures to

pre-industrial era). $I d$. at 630 . Thus, SRM does not necessarily return temperatures to pre-climate change levels in any particular location. There is also likely to be less global precipitation, as followed from the Pinatubo eruption. Id. at 631 .

100. Id. at 631 .

101. Id.

102. Nordhaus considers solar radiation management a somewhat desperate effort to rescue a bad situation, while he considers $\mathrm{CO}_{2}$ removal to be more attractive. See NORDHAUS, supra note 1, at 153,155 .

103. See Sunstein, Precautionary, supra note 73, at 1007-08. Sunstein also finds merit in the weak version of the precautionary principle, which allows regulation even in the face of some uncertainty. See id. at 1053.

104. United Nations Framework Convention on Climate Change art. 2, May 9, 1992, 1771 U.N.T.S. 107. 
anticipate, prevent or minimize the causes of climate change and mitigate its adverse effects." ${ }^{\text {"105 }}$ Rephrasing the precautionary principle, Article 3(3) continues that

$[w]$ here there are threats of serious or irreversible damage, lack of full scientific certainty should not be used as a reason for postponing such measures, taking into account that policies and measures to deal with climate change should be cost-effective so as to ensure global benefits at the lowest possible cost. ${ }^{106}$

Moreover, the goal of the UNFCCC is also precaution. As set forth in Article 2, the Convention's "ultimate purpose" is to stabilize greenhouse gas concentrations at a level that would "prevent dangerous anthropogenic interference with the climate system."107 The appropriate level should be "achieved within a time-frame sufficient to allow ecosystems to adapt naturally to climate change, to ensure that food production is not threatened and to enable economic development to proceed in a sustainable manner."

The UNFCCC itself does not specify the limit of greenhouse gas concentrations required to prevent dangerous interference with the climate system. Section I(4) of the Cancun Agreement, however, adds some specificity on that score. Based on what was then the most recent IPCC report, it sets as a target an increase of $2^{\circ} \mathrm{C}$ above preindustrial levels, and calls for "urgent action to meet this long-term goal, consistent with science and on the basis of equity." 109

As it turns out, the $2{ }^{\circ} \mathrm{C}$ goal can be translated fairly simply into an overall cap on emissions. The most important factor controlling the extent of climate change is quite simple: In the long run, global temperature is controlled simply by total $\mathrm{CO}_{2}$, regardless of when the emissions took place. ${ }^{110}$ The IPCC estimates that in order to keep global temperature increases under $2{ }^{\circ} \mathrm{C}$, cumulative emissions of $\mathrm{CO}_{2}$ need to be kept under a thousand petagrams, which translates into a thousand trillion kilograms ${ }^{111}$ or a billion metric tons (which are slightly larger

105. Id. at art. 3(3).

106. Id.

107. Id. at art. 2.

108. Id.

109. United Nations Climate Change Conference, Cancun, Mex., Nov. 29-Dec. 10, 2010, Decision 1/CP.16, The Cancun Agreements: Outcome of the Work of the Ad Hoc Working Group on Long-term Cooperative Action Under the Convention, I 4, U.N. Doc. No. FCCC/CP/2010/7/Add.1 (Dec. 10-11, 2010), available at http://unfccc.int/resource/docs/2010/cop16/eng/07a01.pdftpage=4.

110. Collins et al., supra note 14 , at 1107.

111. See Rich Green, Petagrams of Carbon, BlogSPOT: How It LoOKS FROM HeRE (July 9, 2011), http://how-it-looks.blogspot.com/2011/07/petagrams-of-carbon.html. 
than the U.S. measure). About half of this amount has already been emitted. ${ }^{112}$ As a matter of basic arithmetic, the total global emissions of $\mathrm{CO}_{2}$ over the entire foreseeable future needs to be kept under 500 million metric tons to reach the $2^{\circ} \mathrm{C}$ goal. Of course, actually achieving this target in terms of total emissions from now forward is not necessarily nearly so simple. ${ }^{113}$

But why choose $2^{\circ} \mathrm{C}$ rather than $1.5^{\circ} \mathrm{C}$ or $2.5^{\circ} \mathrm{C}$ ? Although expected level of harm generally grows substantially between $2^{\circ} \mathrm{C}$ and $4^{\circ} \mathrm{C}$, the expected level of harm even at $2^{\circ} \mathrm{C}$ is not insubstantial. ${ }^{114}$ This also appears to be true of tipping points. For instance, the chances of the Amazon rainforest tipping into drier conditions by the end of the century is significant even at the lower temperature, although it grows at the higher temperature; ${ }^{115}$ and the same is true for abrupt warming in the Arctic. ${ }^{116}$ Indeed, significant climate-induced changes are already taking place even though we are still below the $1^{\circ} \mathrm{C}$ point..$^{117}$ In a summary of the literature, Nordhaus contends that serious tipping points will probably be encountered above $3^{\circ} \mathrm{C}$, but he notes that some scientists argue that anything above $1.5^{\circ} \mathrm{C}$ is dangerous. ${ }^{118}$

Thus, drawing the line between dangerous and safer levels of climate change requires a judgment call. ${ }^{119}$ Two degrees Celsius seems a defensible choice, at least assuming that it is feasible to achieve that target, but the reasons for making this particular choice remain poorly

112. Collins et al., supra note 14, at 1033.

113. Indeed, some scientists argue that it may already be too late to achieve this goal. Wiener, supra note 67 , at 12 . Similarly, Lisa Heinzerling argues that application of the precautionary principle is no longer appropriate in the case of climate change because we are already at the point where some major harms are unavoidable and others can be avoided only through dramatic action. Lisa Heinzerling, Climate Change, Human Health, and the Post-Cautionary Principle, 96 GEO. L.J. 445,445 (2008). From the other end of the spectrum, Nordhaus argues that "limiting the increase in global temperature to $2^{\circ} \mathrm{C}$ is not possible with current or readily available technologies" unless "virtually all countries participate very soon, and do so in an efficient manner." NORDHAUS, supra note 1 , at 181 .

114. See Christopher B. Field et al., Technical Summary, in INTERGovernMENTAL PANEL ON Climate Change, Climate 2014: ImPaCts, AdAPTATION AND VULNERABility 35, 64-65 (2014), available at http://www.ipcc.ch/pdf/assessment-report/ar5/wg2/WGIIAR5-TS_FINAL.pdf.

115. See id. at 64.

116. See id.

117. See id. at $45-46$.

118. NORDHAUS, supra note 1 , at 76-77.

119. Notably, Nordhaus concludes that "policy should aim for limiting temperature to a range between $2^{\circ} \mathrm{C}$ and $3^{\circ} \mathrm{C}$ " above 1900 levels, "depending upon costs, participation rates and discounting." Id. at 8 . In particular, the "lower target is appropriate if costs are low, participation rates are high, and the discount rate on future economic impacts is low." Id. This partial convergence between economic analysis.and the precautionary approach seems significant. 
articulated. Perhaps, however, in the context of an international agreement by so many different countries, it is too much to expect agreement not only on an end result but also about the justification. ${ }^{120}$

\section{EPA's Formal Finding That Carbon Emissions Endanger Human Health and Welfare}

International agreements like the UNFCCC have real-world effects only to the extent that nations take action in line with them. In the United States, federal regulation of greenhouse gases had to await the Supreme Court's 5-4 decision Massachusetts v. EPA. ${ }^{121}$ A group of state and local governments, joined by thirteen leading environmental organizations, petitioned EPA to regulate greenhouse gases under section 202(a)(1) of the Clean Air Act. ${ }^{122}$ That provision requires the Administrator of EPA to issue emissions standards for new motor vehicles for air pollutants that may "reasonably be anticipated to endanger public health or welfare." 23 This is an obviously precautionary standard, both because the danger must only be reasonably anticipated, not proven, and because the standard is the existence of a danger rather than actual or certain harm.

EPA denied the rulemaking petition on two independent grounds. First, it contended that it lacked regulatory authority over greenhouse gases because they are not air pollutants within the meaning of the statute. ${ }^{124}$ Second, it stated that even if it had authority to regulate greenhouse gases, it would choose not to exercise that authority, partly because of residual uncertainty over whether these gases cause global climate change. ${ }^{125}$ In addition EPA concluded, other approaches to addressing climate change, such as international negotiation, were preferable. ${ }^{126}$

Much of the Court's opinion is devoted to the issue of whether any of the petitioners had standing to challenge EPA's decision. ${ }^{127}$ Having

120. As this Article goes to press, negotiators at the Paris climate summit are considering whether to endorse this goal or even a lower temperature. See Eric J. Lyman, Climate Negotiators Mark Movement on Temperature Goal, BLOOMBERG BNA, Dec. 4, 2015.

121. 549 U.S. 497 (2007).

122. Id. at 505 .

123. 42 U.S.C. $\$ 7521$ (a)(1) (2012). For background on the Clean Air Act, see JAMES SALZMAN \& BARTON H. THOMPSON, JR., ENVIRONMENTAL LAW AND POLICY $111-40$ (4th ed. 2014).

124. Massachusetts, 549 U.S. at 513.

125. Id.

126. $I d$.

127. Id. at $516-26$. 
found that at least one of the petitioners did have standing, the majority also concluded that the statute plainly covered greenhouse gases. ${ }^{128}$ This brought it to the question of the agency's discretion not to exercise its jurisdiction. ${ }^{129}$ According to the Court, the EPA had to base its judgment purely on the extent of the risk to public health. ${ }^{130}$ Hence, regulation was mandatory unless EPA found that greenhouse gases do not contribute to climate change ${ }^{131}$ or that the uncertainty was so great that it prevented EPA from making a reasoned judgment. ${ }^{132}$

On remand, EPA made a formal finding that greenhouse gas emissions endanger human health or welfare, ${ }^{133}$ a finding that was upheld by the D.C. Circuit in Coalition for Responsible Regulation, Inc. v. EPA. ${ }^{134}$ In that case, the challengers disputed the EPA findings on several grounds. First, they argued that EPA had, in effect, delegated its judgment to bodies such as the IPCC and the National Research Council by relying on their scientific assessments. ${ }^{135}$ The court rejected this argument as "little more than a semantic trick." "136 In reality, the court said, EPA had merely made normal use of the existing scientific literature, and carefully evaluated the quality of these sources before relying on them. ${ }^{137}$

Second, the challengers argued that the scientific evidence did not

128. Id. at $528-32$.

129. Id. at $532-35$.

130. Id. at 533-34. There were two dissents, both joined by the same four Justices. Chief Justice Roberts's dissent argued that the plaintiffs lacked standing. $I d$. at 535 (Roberts, C.J., dissenting). For a discussion of the standing issue, see generally Daniel A. Farber, A Place-Based Theory of Standing, 55 UCLA L. REv. 1505 (2008). Justice Scalia's dissent argued that the statute was at least ambiguous, entitling EPA's interpretation to deference, and that EPA could also consider other, nonstatutory factors in determining whether or not to regulate. Massachusetts, 549 U.S. at 549 (Scalia, J., dissenting). For an extensive discussion of the latter aspect of the case, see Daniel A. Farber, Taking Costs into Account: Mapping the Boundaries of Judicial and Agency Discretion, HARV. ENVTL. L. REV. (forthcoming 2016).

131. Massachusetts, 549 U.S. at 533.

132. Id. at 534 .

133. Endangerment and Cause or Contribute Findings for Greenhouse Gases Under Section 202(a) of the Clean Air Act, 74 Fed. Reg. 66,497 (Dec. 15, 2009) (to be codified at 40 C.F.R. pt. 1).

134. 684 F.3d 102, 113 (D.C. Cir. 2012). The Supreme Court granted certiorari on another issue in the case and reversed in part on that issue in Utility Air Regulatory Group v. EPA, _ U.S. 134 S. Ct. 2427 (2014).

135. Coalition, 684 F.3d at 119.

136. Id. at 120. The court's impatience with this argument is also reflected in its comment that "EPA is not required to re-prove the existence of the atom every time it approaches a scientific question." Id.

137. Id. 
support the finding of endangerment. ${ }^{138}$ The court carefully recounted the basis for this finding in the scientific evidence, concluding that there was substantial evidence that climate change endangers health and welfare. ${ }^{139}$ Industry argued, however, that there was too much uncertainty to support EPA's conclusion. ${ }^{140}$ In rejecting the industry's argument, the court stressed that the statute is precautionary in nature and that to wait for certainty would block preventive regulation. ${ }^{141}$ In the court's view, the statute "requires a precautionary, forward-looking scientific judgment," because of the need "to prevent reasonably anticipated endangerment from maturing into concrete harm." 142

Two other arguments that were made before the agency are also worth mentioning. First, some of the parties commenting on the rule argued that EPA had improperly based its endangerment finding on possible harm to foreign populations. ${ }^{143}$ As we will see, this is a concern that has also been raised concerning the social cost of carbon. EPA made it clear, however, that although it considered global effects of greenhouse gases, it did so only in the course of determining potential domestic harm. ${ }^{144} \mathrm{~A}$ second question concerned the relevant time period for assessing danger. Rejecting arguments for focusing only on current impacts, EPA's analysis was based on the next few decades, in some cases extending up to the end of the century. ${ }^{145}$

Note that because it was making a qualitative assessment of the degree of danger, EPA was not required to quantify the probability or to set a discount rate, two major issues in the economic analysis of climate change. The challengers did argue that EPA had failed to quantify the point at which greenhouse gases pose a danger, the specific types of harms, or the risks and impacts of climate change. ${ }^{146}$ But the court rejected the idea that EPA was required to set a numerical threshold in finding endangerment. "Quite the opposite," the court said, the endangerment finding requires a "case-by-case, sliding-scale approach to

138. Id

139. Id. at $120-21$.

140. Id. at 121 .

141. Id.

142. Id. at 122 .

143. Endangerment and Cause or Contribute Findings for Greenhouse Gases Under Section 202(a) of the Clean Air Act, 74 Fed. Reg. 66,497, 66,514 (Dec. 15, 2009) (to be codified at 40 C.F.R.pt. 1).

144. Id.

145. Id. at 66,524 .

146. Coalition, 684 F.3d at 122. 
endangerment." 147

EPA's approach to the endangerment finding has been considered an epitome of the precautionary principle. ${ }^{148}$ Moreover, scientific developments since the finding was made have only strengthened the conclusion that climate change is a threat to human health and welfare. $^{149}$

\section{The Threat of Climate Change to the Survival of Polar Bears}

Some of the key impacts of climate change are ecological. The evidence already shows significant effects of climate change on animal and plant life. ${ }^{150}$ According to climate scientists, given the relatively small degree of global warming to date, "it is astounding that the consequences of warming on nature are already evident." "F1 For this reason, irreversible harm could occur to ecosystems as their resilience levels are exceeded, including the possibility that "species that have lived on our planet for hundreds of thousands or even millions of years will rapidly vanish from the face of the Earth." ${ }^{152}$ Indeed, some ecologists are speaking of the current era as akin to the great extinction events in the geological record. ${ }^{153}$ Yet, specific effects on particular ecosystems are harder to predict than purely physical changes. ${ }^{154}$

Both the potential for extinction and the difficulties of making precise predictions pose problems for the legal system. In the United States, the key protection for biodiversity is the Endangered Species Act (ESA). ${ }^{155}$

147. Id. at 122-23. In addition to this argument, the challengers also argued that EPA should have reconsidered its finding in light of the so-called "climategate" incident, involving hacking of emails from climate scientists. See id. at 124 (discussing the leaks of email by climate scientists commonly called "climategate" by climate change deniers). The court found that EPA had an ample basis for rejecting the requests for reconsiderations. Id. at 124-26.

148. See Leslie Carothers, Upholding EPA Regulation of Greenhouse Gases: The Precautionary Principle Redux, 41 ECOLOGY L.Q. 683 (2014).

149. See id. at 729-35.

150. ARCHER \& RAHMSTORF, supra note 1, at 152-58.

151. Id. at 159 .

152. Id. at 163 .

153. Gerardo Ceballos et al., Accelerated Modern Human-Induced Species Losses: Entering the Sixth Mass Extinction, 1 SCI. ADVANCES 5 (2015), available at http://advances.sciencemag.org/content/advances/1/5/el400253.full.pdf. The authors say they avoid using techniques such as species-area models that might exaggerate species loss, $i d$. at 2 , but that even using conservative assumptions, "[t] he evidence is incontrovertible that recent extinction rates are unprecedented in human history and highly unusual in Earth's history," id. at 4.

154. ARCHER \& RAHMSTORF, supra note 1 , at 152.

155. 16 U.S.C. $\$ 1531$ (2012). For a critique of the statutes and suggested alternatives, see JoNATHAN H. ADLER ET AL., REBUILDING THE ARK: NEW PERSPECTIVES ON ENDANGERED SPECIES 
A short survey of the statute is in order as a prelude to discussion of its treatment of climate change.

The first step in applying the statute is the listing of an endangered or threatened species. Under section 4 of the Act, the Secretary of the Interior (in the case of land-based and freshwater species) or the Secretary of Commerce (in the case of marine species) must consider the following factors:

(A) Present or threatened habitat change;

(B) Over-exploitation of the species;

(C) Disease or predation;

(D) The adequacy of existing regulatory mechanisms; and

(E) Any other natural or manmade factors affecting its continued existence. ${ }^{156}$

Climate change falls under heading (A) as a cause of habitat modification or destruction, as well as under the catchall heading (E) as a "nature or manmade factor."

The Act defines an "endangered species" as "any species which is in danger of extinction throughout all or a significant portion of its range." 157 A "threatened species," on the other hand, is "any species which is likely to become an endangered species within the foreseeable future throughout all or a significant portion of its range." 158 In the listing of a species, the Secretary may not consider economic impacts. So much for cost-benefit analysis. Rather, the Secretary must make the determination "solely on the basis of the best scientific and commercial data available to him.",159

The effects of listing are substantial. First, the species obtains stringent protection on federal lands. Section 7(a)(2) of the Act requires that federal agencies insure that any action they authorize, fund, or carry out is not likely to jeopardize any endangered or threatened species or its

ACT REFORM (Jonathan H. Adler ed., 2011).

156. 16 U.S.C. $\$ 1533(\mathrm{a})$.

157. Id. $\$ 1532(6)$.

158. Id. $\$ 1532(20)$.

159. Id. § 1533(b)(1)(A); see Ctr. for Biological Diversity v. Badgley, 335 F.3d 1097, 1101 (9th Cir. 2003) (holding that the decision not to list was based only on best available scientific and commercial data and therefore was not arbitrary or capricious); N.M. Cattle Growers Ass'n v. U.S. Fish \& Wildlife Servs., 248 F.3d 1277, 1282 (10th Cir. 2001) (holding that the Service may not consider economic impacts in listing decision). 
critical habitat. ${ }^{160}$ Second, section 9 of the Act, arguably the most controversial aspect of the statute, establishes a broad prohibition against "taking" endangered species. ${ }^{161}$ Unlike section 7, which applies only to federal agencies, section 9 applies to "any person subject to the jurisdiction of the United States." 162 The Supreme Court has held that the "taking" prohibition applies not only to direct killing but also to habitat modifications that proximately cause the death of members of the species. ${ }^{163}$

It seems clear that agencies cannot simply ignore climate change in listing decisions. ${ }^{164}$ For instance, in Greater Yellowstone Coalition $v$. Servheen ${ }^{165}$ the court struck down a decision to delist the Yellowstone grizzly bear for this reason. ${ }^{166}$ Climate change has also been a key consideration in a number of listing decisions involving marine species. ${ }^{167}$ In addition, climate change has also been an increasingly prevalent consideration in new and revised recovery plans for species, ${ }^{168}$ including two species of coral. ${ }^{169}$

For present purposes, the issue of greatest concern is how to handle issues of uncertainty in terms of the effect of climate change on

160. 16 U.S.C. $\S 1536($ a)(2). For an explanation of how this provision is applied, see J.B. Ruhl, Climate Change and the Endangered Species Act: Building Bridges to the No-Analog Future, 88 B.U. L. REV. 1, 43-44 (2008). The critical habitat component of this provision is frequently ignored in practice. See Dave Owen, Critical Habitat and the Challenge of Regulating Small Harms, 64 FLA. L. REV. 141, 146 (2012) (noting, however, that other provisions have been used to provide significant habitat protection).

161. 16 U.S.C. $\$ 1538(a)(1)$. "Take" has been broadly defined to include harass, harm, pursue, hunt, shoot, wound, kill, trap, capture, or collect.

162. Id. $\S 1538(\mathrm{~d})(1)$.

163. Babbitt v. Sweet Home Chapter of Cmtys. for a Great Or., 515 U.S. 687, 690 (1995). Although there is an argument that the ESA might prohibit carbon emissions as a "taking" of endangered species, the statute seems to provide a clumsy mechanism for addressing emissions. The ESA is designed to deal with discrete projects or individual actions that threaten a species, not with widely dispersed human activity such as carbon emissions by the world's energy system. Ruhl, supra note 160 , at 6 . Thus, the ESA is arguably a poor fit with climate mitigation efforts. For instance, the requirement that an action proximately cause the death of members of the species arguably may exclude carbon emissions. Id. at 41 . But where species are not already irreversibly doomed by climate change, the statute could provide impetus to protect remaining populations from other threats and to help species in overcoming barriers to migration to safer havens. Id. at 13 .

164. Ruhl, supra note 160 , at 33 .

165. 665 F.3d 1015 (9th Cir. 2011).

166. See id. at $1025-26$.

167. Erin Seney et al., Climate Change, Marine Environments, and the U.S. Endangered Species Act, 27 CONSERVATION BIOLOGY 1138, 1142 (2013).

168. Id. at 1143 .

169. Robin Kundis CRAIG, Comparative OCEAN Governance: Place-Based Protection IN AN ERA OF Climate ChaNGE 11 (Kurt Deketelaere \& Zen Makuch eds., 2012). 
individual species. The emblematic victim of climate change is the polar bear, whose listing as threatened ${ }^{170}$ was upheld by the Ninth Circuit in the appropriately named In re Polar Bear ${ }^{171}$ case. The Polar Bear case involved a number of issues relating to application of the statute, including potential uncertainties regarding the impact of climate change on the bears.

We are already familiar with issues about the validity and accuracy of models, and similar issues were present in the Polar Bear case as well. EPA had relied in part on two models of polar bear populations developed by the United States Geological Service (USGS). ${ }^{172}$ One model was simply based on the past statistical relationship between the area of sea ice and polar bear populations; the other included other potential stressors as well as indications of the availability (not just the area) of the ice. ${ }^{173}$ The FWS itself indicated doubts about these models, since the first one relied on a dubious assumption of constant population densities while the second was in an early stage of development. ${ }^{174}$ The court dismissed this challenge to the regulation, however, because the agency used the models only for the limited purpose of confirming trends indicated by other evidence. ${ }^{175}$

The challengers then criticized the agency for relying on the IPCC definition of "likely" (67-90\%) in applying the statutory standard of whether polar bears were likely to become endangered in the foreseeable

170. Threatened species may receive less protection under the ESA than endangered ones. Section 1533(d) allows the Secretary of the Interior (or the Secretary of Commerce in the case of marine species) to provide only the degree of protection "necessary for the conservation of the species." 16 U.S.C. $\S 1533$ (d) (2012).

171. 709 F.3d 1, 9 (D.C. Cir. 2013). The court had little difficulty affirming the listing decision in this landmark case:

The Listing Rule rests on a three-part thesis: the polar bear is dependent upon sea ice for its survival; sea ice is declining; and climatic changes have and will continue to dramatically reduce the extent and quality of Arctic sea ice to a degree sufficiently grave to jeopardize polar bear populations. No part of this thesis is disputed and we find that FWS's conclusion-that the polar bear is threatened within the meaning of the ESA-is reasonable and adequately supported by the record ....

Where, as here, the foundational premises on which the agency relies are adequately explained and uncontested, scientific experts (by a wide majority) support the agency's conclusion, and Appellants do not point to any scientific evidence that the agency failed to consider, we are bound to uphold the agency's determination. Therefore we affirm the District Court's decision to uphold the Listing Rule.

Id. at 8-9. Other arctic species also face peril because of climate change. See CRAIG, supra note 169 , at 49.

172. Polar Bear, 709 F.3d at 12.

173. Id. at 13 .

174. Id.

175. Id. at 14 . 
future. ${ }^{176}$ But the court found this to be an implausible interpretation of the EPA's language when read in context. ${ }^{177}$ Instead, the court concluded that the agency followed the IPCC practice only when stating its confidence in climate forecasts and otherwise applied the term in a commonsensical (though not precisely defined) way. ${ }^{178}$

Finally, the challengers contested the time period considered by the agency. The statutory definition of a threatened species is one that is likely to become endangered in the foreseeable future. ${ }^{179}$ The EPA defined "foreseeable" as forty-five years. ${ }^{180}$ The agency chose this timeframe as being the period during which it could make a reliable assessment of the effect of threats on the species. ${ }^{181}$ The forty-five year period was essentially the time between the agency's decision and midcentury, and was chosen because climate models were in essential agreement until about that time. ${ }^{182}$ Thus, the agency focused on a time period during which the uncertainty was lower.

Predictions about the future of a species are hampered by the unpredictability of ecological systems. Uncertainty about the severity of climate change necessarily complicates the problem further. Nevertheless, the EPA seems to have made a thoughtful decision despite these uncertainties, helped along by a precautionary statutory standard.

The applications of the precautionary principle that we have considered in this section of the Article seem successful in terms of identifying when climate risks need to be taken into account. On the other hand, the precautionary principle's call for "cost-effective" responses is not terribly informative. It does not specify how much society should spend to reduce the risk or what amount of risk reduction is called for. Part III discusses cost-benefit analysis, an approach that is much more explicit in its treatment of tradeoffs, although it has some problems of its own.

179. 16 U.S.C. $\S 1532(20)$ (2012).

180. Polar Bear, 709 F.3d at 15.

181. Id.

182. Id. at 15-16. 


\section{USING COST-BENEFIT ANALYSIS AS THE BASIS FOR CLIMATE POLICY}

The subject of cost-benefit analysis does not lack for controversy. Although many economists and some legal scholars favor the use of cost-benefit analysis for government regulation, ${ }^{183}$ environmentalists are often sharply opposed. ${ }^{184}$ For instance, two leading environmentalist critics of cost-benefit analysis ${ }^{185}$ contend that "cost-benefit analysis promotes a deregulatory agenda under the cover of scientific objectivity." 186 In particular, they argue that cost-benefit analysis requires that analysts settle on numbers for all costs and benefits, regardless of uncertainty, putting pressure on them to ignore uncertainties completely or to ignore more extreme possibilities even when they do acknowledge variability. ${ }^{187}$ Thus, they find cost-benefit analysis especially unhelpful in the face of uncertainty.

Unlike these critics, some writers who are sympathetic to environmental protection embrace cost-benefit analysis. ${ }^{188}$ Although they view it as just one input into the ultimate regulatory decision, ${ }^{189}$ Richard Revesz and Michael Livermore argue that cost-benefit analysis is needed to determine when further spending on risk reduction is no longer worthwhile. ${ }^{190}$ They argue that just as environmental impacts of actions must be taken into account, so should economic impacts of

183. For an introduction to opposing views of cost-benefit analysis, see MATTHEW D. ADLER \& ERIC A. Posner, Cost-Benefit analysis: ECONOMIC, PhIlosophical, AND Legal PerspeCtives (Matthew D. Adler \& Eric A. Posner eds., 2001).

184. For citations to some of the key critical works, see Kysar, supra note 62 , at $6 \mathrm{n} .23$.

185. ACKERMAN \& HEINZERLING, supra note 61. They make it clear, however, that their quarrel is with the economic methodology of cost-benefit analysis, not with taking costs and benefits into account:

[A]nalysis of costs and benefits, in lowercase letters, is an essential part of any systematic thought about public policy, and has always been involved in government decision making.

Our criticism concerns the much narrower doctrine of Cost-Benefit Analysis, which calls for a specific, controversial way of expressing and thinking about costs and benefits.

Id. at 9.

186. Id. at 8-9; see also id. at 11-12 ("Cloaked in the language of scientific objectivity, economic arguments have repeatedly played a partisan role.").

187. Id. at 224 .

188. For references to the writings of some of the leading academic supporters of cost-benefit analysis, see Kysar, supra note 62 , at 5 .

189. See id. at 15-16.

190. See Richard L. Revesz \& Michael A. Livermore, Retaking Rationale: How CostBenefit analysis Can Better Protect the Environment and Our Health 12, 15-16 (2008). 
regulation. ${ }^{191}$ They also view cost-benefit analysis as a way of disciplining the wide discretion given to administrative agencies, thereby ensuring that decisions are made on the basis of reasoned analysis and uniform criteria. ${ }^{192}$

Regardless of these debates, cost-benefit analysis is a practical imperative for federal agencies under long-standing executive branch policies. For almost thirty years, regulatory agencies like EPA have been required to perform cost-benefit analyses that are subject to review by the Office of Management and Budget (OMB). ${ }^{193}$

Given that executive orders requiring cost-benefit analysis leave agencies with little choice but to engage the economics of their regulatory decisions, we will focus on their application of cost-benefit analysis to climate policy -and in particular, on the difficulties involved in putting monetary value on the benefits of reducing carbon emissions. Part III.A provides an explanation of some of the crucial issues involved in determining those benefits and then takes a deep dive into the models economists use to make this calculation. Part III.B then turns to the federal government's effort to use these models to determine the social cost of carbon and to the debates over that effort.

\section{A. Issues in Calculating the Costs and Benefits of Climate Policy}

Cost-benefit analysis of climate policies requires consideration of three key issues: how to forecast economic impacts, how to make tradeoffs between harms in the far future and mitigation expenses today, and how to take the possibility of unexpectedly catastrophic outcomes into account. These issues are discussed in turn.

191. Id. at 13 .

192. Id.

193. Regulatory review takes place within the Office of Information and Regulatory Affairs (OIRA). For a description of the development of OMB's role in regulatory oversight, along with some useful suggestions for improving cost-benefit analysis, see Daniel H. Cole, "Best Practice" Standards for Regulatory Benefit-Cost Analysis, 23 RES. L. \& ECON. 1 (2007). See generally ADLER \& POSNER, supra note 183 (collecting papers reflecting the spectrum of views about cost-benefit analysis and its validity); Don Bradford Hardin, Jr., Why Cost-Benefit Analysis? A Question (and Some Answers) About the Legal Academy, 59 ALA. L. REV. 1135, 1136 (2008) (describing the rise of attention to cost-benefit analysis in the legal academy). Finally, for information about the current operation of OMB, see Cass R. Sunstein, Commentary, The Office of Information and Regulatory Affairs: Myths and Realities, 126 HARV. L. REV. 1838 (2013). 


\section{The Difficulty of Forecasting Economic Harm from Climate Change}

Many individual elements of the economic impact analysis for climate change are the subjects of serious debate. These would cause problems for cost-benefit analysts even if science could provide a perfect forecast of future global temperatures. For instance, some economists find an overall positive effect on U.S. agriculture (but with very large regional variations), ${ }^{194}$ while others find substantial negative effects. ${ }^{195}$

More broadly, modeling the long-term economic impact of climate change and the costs of adjusting unavoidable climate change (adaptation) and reducing carbon emissions (mitigation) involves tremendous challenges. ${ }^{196}$ According to the Congressional Research Service, "[1]ong-term projections... should be viewed with skepticism... The finer the detail, the greater the skepticism should be." 197 Even the more confident economic modelers ${ }^{198}$ admit that attempts to estimate the impacts of climate change continue to be highly "speculative." 199 It is hard to forecast the trajectory of the economy over

194. See Olivier Deschênes \& Michael Greenstone, The Economic Impacts of Climate Change: Evidence from Agricultural Output and Random Fluctuations in Weather, 96 AM. ECON. REV. 354, 377,381 (2007) (finding that the most likely result of climate change on American agricultural profits is an annual increase in profits of roughly $4 \%$, but with California losing $15 \%$ ). Note, however, that this study excludes possible impacts of increases in extreme events such as storms and droughts. See id. at 380 . Extreme local events are a significant factor even in the absence of extreme global temperature changes. For instance, the latest models show indications of more intense hurricanes in the remainder of this century. See Richard A. Kerr, Models Foresee MoreIntense Hurricanes in the Greenhouse, 327 SCIENCE 399 (2010).

195. See Wolfram Schlenker et al., The Impact of Global Warming on U.S. Agriculture: An Econometric Analysis of Optimal Growing Conditions, 88 REV. ECON. \& STAT. 113, 122-24 (2006) (estimating the potential impact on farmland values east of the one-hundredth meridian for a range of warming scenarios and concluding that aggregate losses could be quite severe if fossil fuel use increases).

196. For a good overview of modeling issues, see J.C. Hourcade et al., Estimating the Costs of Mitigating Greenhouse Gases, in ClIMATE CHANGE 1995: ECONOMIC AND SOCIAL DIMENSIONS OF Climate CHANGE 263, 268 (James P. Bruce et al. eds., 1996), available at https://www.ipcc.ch/ipccreports/sar/wg_IIL/ipcc_sar_wg_III_full_report.pdf (discussing the "critical determinants" likely to influence the overall cost of climate policies and of the main methodologies employed to account for them).

197. Darren Samuelsohn, Climate: Uncertain Economic Models Create Headaches for Senate Panel, ENV'T \& ENERGY DAILY 1, 2 (Oct. 14, 2009), available at http:/www.eenews.net/ Greenwire $/ 2009 / 10 / 14 /$ archive $/ 5$ ?terms $=$ Climate $\% 3 A+$ Uncertain + Economic + Models + Create + Head aches+for+Senate+Panel.

198. William D. Nordhaus \& Joseph G. BOYER, WARMING THE WORID: ECONOMiC MODELS OF GLOBAL WARMING (2000).

199. Id. at 86 (conditioning their model on the need for a "detailed inventory and valuation of climatically sensitive regions for validation"). 
future decades. For example, no forecaster in 1970 could have predicted the explosive growth of personal computers-and the resulting economic boom - that occurred only a few decades later. No forecaster in 1970 could have predicted the creation of complex financial derivatives, nor could they have predicted that those derivatives would threaten major economic depression in the new millennium.

Forecasts necessarily rely on inherently uncertain projections about future behavior. Forecasting future use of adaptation measures is important in determining the harms created by climate change. But even when adaptation is possible, it may not take place for institutional reasons. For instance, the history of federal flood control gives little ground to be optimistic that flood control projects will be optimally designed and built. ${ }^{200}$ Or perhaps for psychological reasons individuals will fail to take sufficient action to protect themselves. Moreover, because climate change scenarios are based on projections of future emissions, they implicitly make assumptions about future political and economic developments, which are imperfectly known (to say the least).

Thus, forecasting the costs of climate change involves making predictions over a long period of time about economic and institutional developments. These problems are inherent in any attempt to make longterm predictions about the state of society. But cost-benefit analysis of climate change poses two additional difficult issues. One issue concerns the need to compare future benefits and current mitigation costs, given that carbon emissions have such long-term effects. The other involves the difficulty of taking into account the possibility of tipping points that would result in severe impacts. These are discussed below.

\section{How Much Should We Discount Future Harms?}

Carbon dioxide emitted today will linger in the atmosphere for two to three centuries, continuing to cause climate impacts, and global temperatures will remain high, even after we eliminate emissions, for an even longer time. ${ }^{201}$ Conversely, a dollar invested in reducing emissions today will provide benefits over the same period of time. In assessing the value of this investment, we need to take into account the long time span

200. See Matthew D. Zinn, Adapting to Climate Change: Environmental Law in a Warmer World, 34 ECOLOGY L.Q. 61, 72-73 (2007) (arguing that adaptation presents great institutional and political difficulties, which may prevent it from being successfully managed to minimize ecological or other impacts).

201. According to Nordhaus, if we do nothing about climate change until 2100 and then stop all emissions, " $\mathrm{CO}_{2}$ would remain well above preindustrial levels for a millennium, and global temperature would peak at around $4^{\circ} \mathrm{C}$ above 1900 levels." NORDHAUS, supra note 1 , at 163 . 
involved.

Economists use a technique called discounting for this purpose. ${ }^{202}$ The basic premise is that people generally prefer consumption today over consumption tomorrow. Suppose someone has the choice between getting some amount of money today and $\$ 100$ a year from now. There are several reasons why a person might be willing to accept less than a $\$ 100$ today rather than waiting a year for the full amount-one of them is simple impatience, and another is that a person might expect to have more money next year anyway, so that person would need the money more badly today.

The discount rate measures the degree of preference for the presentfor instance, a $10 \%$ discount rate means that receiving $\$ 100$ a year from now is only as good as receiving $\$ 90$ today (even apart from inflation). The key point is that the value of receiving a future dollar falls over time in accordance with the discount rate. Over a long period of time-the kind of time period involved with climate change-the changes are really dramatic because discounting compounds as the years go on. For instance, at a $10 \%$ discount rate, even without inflation, $\$ 100,000$ in 2115 equates to about $\$ 7.30$ today. ${ }^{203}$ From something that would buy two Mercedes $\mathrm{C} 400 \mathrm{~s}$ and leave almost a thousand dollars in change, ${ }^{204}$ instead we get a number closer to the cost of a meal at McDonald's. ${ }^{205}$

Because of the very long-term effects of climate change, discounting

202. A concise introduction to discounting can be found in NiCHOLAS STERN, THE ECONOMICS of Climate Change: The Stern Review 50-60 (2007). As Stern points out, uncertainty about future growth implies that the discount rate declines for events further in the future. See id. at 5657. For some reflections on the problems raised by consideration of time in cost-benefit analysis even beyond discounting, see Arden Rowell, Time in Cost-Benefit Analysis, 4 U.C. IRVINE L. REV. 1215 (2014). An excellent overview of the debate over the Stern report can be found in Daniel H. Cole, The Stern Review and Its Critics: Implications for Theory and Practice of Cost-Benefit Analysis, 48 NAT. RESOURCES J. 1 (2008).

203. The easiest way to generate these figures is to use an online app. See Discounted Present Value Calculator, AQUA-CALC, http://www.aqua-calc.com/page/discounted-present-valuecalculator (last visited Oct. 21, 2015). Nordhaus uses another set of illustrative figures, showing that the present value of a $\$ 100$ million reduction in damages is about $\$ 60$ million at a $1 \%$ rate but falls by almost a factor of five at a $4 \%$ rate and by a about a factor of sixty-five at $10 \%$. NORDHAUS, supra note 1 , at 191

204. The list price for the 2015 Mercedes-Benz C400 4MATIC Sedan is $\$ 49,515$. See MercedezBenz C-Class Sedan, CAR \& DRIVER, http://www.caranddriver.com/mercedes-benz/cclass/pricing/options (last visited Oct. 21, 2015).

205. Indeed, if people are relatively indifferent to the plight of future generations as opposed to their own welfare, the amount of discounting could be even higher in the intergenerational context. Another way of seeing the effect of discounting is that if a ton of carbon caused $\$ 1000$ in damage every single year forever, we would only be willing to pay $\$ 10,000$ to avoid the harm. That is equal to the damages for only the first ten years, as compared to the huge cumulative amount of damage after that time period. 
is a crucial factor in the economic analysis. But even economists find it disquieting that discounting "forces us to say that what we might otherwise conceptualize as monumental events 'do not much matter' when they occur in future centuries or millennia." ${ }^{206}$ Even if we assume that discounting is appropriate when dealing with the effect of policies on current generations, its application to future generations raises graver issues. After all, their value as human beings is equal to that of people today, yet discounting systematically downgrades their interests, sometimes to the point of insignificance. ${ }^{207}$

One defense of discounting is that funds spent to avoid climate change could be spent on other purposes, which might be more beneficial to future generations. Thus, we might want to engage in discounting in the interest of future generations in order to maximize the benefits to them from present-day investments. Market rates represent the opportunity cost of investment, so this argument suggests that we should avoid climate mitigation projects unless they offer equal returns. ${ }^{208}$ One problem with this argument is that climate change might have catastrophic effects on later generations that cannot be offset by increased savings. ${ }^{209}$

If discounting is indeed a valid approach, other, more technical difficulties, must be confronted. As it turns out, the number chosen as the discount rate is very important; small differences can be amplified over time into a big difference in the outcome. This can be seen from the following table:

206. Martin L. Weitzman, Why the Far-Distant Future Should Be Discounted at Its Lowest Possible Rate, 36 J. ENVTL. ECON. \& MGMT. 201, 201 (1998).

207. Some influential economists have argued that discounting should not include any reduction in present value based on the intrinsic difference between future and present consumption, as opposed to other factors such as the possibility of increasing wealth over time. See STERN, supra note 202 , at $35-36$.

208. This argument is developed in ERIC A. Posner \& David Weisbach, Climate Change JUSTICE 144 (2010).

209. Another argument for discounting is that, given economic growth, future generations are likely to be much wealthier than current generations, even taking into account climate change. Why should present generations sacrifice to make future generations even richer-isn't this in effect transferring money from the (relatively) poor to the (relatively) rich? But future growth rates may be uncertain. Even today, although technology is a constant, individual countries have much different records of growth, which suggests that other factors are also crucial. Given the limits on how well we understand growth, we may not have any real assurance that present growth rates will continue. A related argument is that if we wait we will be able to limit climate change much more cheaply than today with new technology, but this is also highly speculative. Any new technology would have to contend with a problem that had already become much worse due to delay. 


\begin{tabular}{|c|c|c|}
\hline \multicolumn{3}{|c|}{ Table 3-Effect of Discount Rate on Present Value } \\
\hline Discount rate & $\begin{array}{l}\text { Present value of \$6 million } \\
\text { received in 20 years }\end{array}$ & $\begin{array}{l}\text { Present value of \$6 million } \\
\text { received in 40 years }\end{array}$ \\
\hline $10 \%$ & $\$ 894,000$ & $\$ 132,570$ \\
\hline $7 \%$ & $\$ 1,560,000$ & $\$ 400,682$ \\
\hline $5 \%$ & $\$ 2,261,337$ & $\$ 852,274$ \\
\hline $3 \%$ & $\$ 3,324,000$ & $\$ 1,839,341$ \\
\hline $2 \%$ & $\$ 4,037,828$ & $\$ 2,717,342$ \\
\hline $1 \%$ & $\$ 4,917,267$ & $\$ 4,029,918$ \\
\hline
\end{tabular}

As the table shows, cutting the discount rate from $7 \%$ to $3 \%$ approximately doubles the present value of the eventual benefit, from $\$ 1.56$ million to over $\$ 3$ million. Cutting the rate another $2 \%$ would bring the present value up to nearly $\$ 5$ million. Over longer periods of time, the differences are even more dramatic. For instance, over forty years, raising the discount rate from $3 \%$ to $7 \%$ reduces the present value almost $80 \%$, from almost $\$ 2$ million to under half a million. Over eighty years, the difference is $\$ 26,934$ versus $\$ 559,494$, an almost twenty-fold difference-something like the difference between the price of a car and the price of a house..$^{210}$

The bottom line is that discounting makes a big difference in assessing costs and benefits over long periods of time, and that difference is quite sensitive to changes in rates. Over multiple-decadal time scales, a minor shift in the discount rate can dramatically impact the analysis of whether additional precautions are warranted. Given the very long-term effects of climate change, a small change in the discount rate can drive huge changes in the results. Yet, there is no consensus about what discount rate to use for climate change. ${ }^{211}$

210. The reader can confirm these figures using any of the readily available discounting tools and a quick calculation.

211. For a concise overview of the relevant literature, see Charles Kolstad et al., Social, Economic, and Ethical Concepts and Methods, in INTERgovernMENTAL PANEL ON ClimATE Change, Climate Change 2014: Mitigation of Climate Change, 207, 228-32 (Marlene Attz et al. eds., 2014), available at https://www.ipcc.ch/pdf/assessment-report/ar5/wg3/ ipcc_wg3_ar5_full.pdf. One problem has been a lack of empirical data about returns on very longterm investments. A recent study based on real estate prices suggests a discount rate of $2.6 \%$ for investments longer than a century. See Stefano Giglio et al., Long-Run Discounting and Climate Change: Evidence from Real Estate (July 2015) (unpublished manuscript), available at http:/ssrn.com/abstract $=2639748$. 


\section{Assessing the Risk of Tipping Point and Catastrophic Outcomes}

Another key issue in terms of the economic analysis is the possibility of unexpectedly bad outcomes, such as major melting of ice sheets, releases of large amounts of methane, and halting of the Gulf Stream. ${ }^{212}$ For instance, consider a scenario in which warming causes the release of methane, which accelerates the warming, which releases more methane, until climate change has gone out of control. Thus, the concern is whether the climate system might surprise us with extremely bad outcomes which do not seem terribly likely but whose odds are difficult to estimate. William Nordhaus, who pioneered the economic models of climate change, explains how these kinds of risks affect the analysis:

[W] might think of the large-scale risks as a kind of planetary roulette. Every year that we inject more $\mathrm{CO}_{2}$ into the atmosphere, we spin the planetary roulette wheel...

A sensible strategy would suggest an insurance premium to avoid the roulette wheel in the Climate Casino.... We need to incorporate a risk premium not only to cover the known uncertainties such as those involving climate sensitivity and health risks but also the zero and double zero uncertainties such as tipping points, including ones that are not yet discovered. ${ }^{213}$

The difficulty, as Nordhaus admits, is trying to figure out the extent of the premium. Another recent book by two leading climate economists argues that the downside risks are so great that " $[\mathrm{t}] \mathrm{he}$ appropriate price on carbon is one that will make us comfortable enough to know that we will never get to anything close to $6^{\circ} \mathrm{C}\left(11^{\circ} \mathrm{F}\right)$ and certain eventual catastrophe." 214 Although they admit that "never" is a bit of an overstatement-reducing risks to zero is impractical - they clearly think it should be kept as low as feasibly possible. ${ }^{215}$ Not all economists would agree with that view, but there seems to be a growing consensus that the possibility of catastrophic outcomes should play a major role in determining the price on carbon. ${ }^{216}$ The IPCC expresses high confidence

212. NORDHAUS, supra note 1, at 56-66. Nordhaus observes that "all the systems involved in the analysis of tipping points are perplexing because they involve poorly understood dynamics and nonlinear responses." $I d$. at 63 .

213. Id. at $141-42$.

214. WAGNER \& WEITZMAN, supra note 37 , at 78 (emphasis in original).

215. Id.

216. Reaching a similar conclusion after extensive modeling exercises, another group of researchers concludes: "The uncertainties involved in our ability to model the future climate and climate change damages in addition to the potential for non-linear climate responses with large 
that the impacts of extreme events (such as more hurricanes like Katrina or more droughts like the current one in California) are likely to be more important economically than average effects of climate change. ${ }^{217}$ But beyond these localized extreme impacts, the possibility that warming will be unexpectedly severe poses risks at the global level.

\section{B. Forecasting the Cost of Climate Change with Integrated Assessment Models}

These issues regarding cost-benefit analysis of climate change are not merely theoretical. Instead, they are crucial factors in designing the economic models of climate change used by economists and the federal government. These Integrated Assessment Models (IAMs) are computer simulations that couple some kind of model of the economy and energy sector with a stripped-down climate model, in order to project the future costs of reducing carbon and the benefits of doing so. ${ }^{218}$

It may help to unpack the contents of the previous paragraph a bit. To estimate the costs of climate change, economists must begin with a model of how the economy would grow in the absence of climate change. The modeler can then add some assumptions about what emissions control policies will be in effect, and then estimate on the basis of the growth model and the emissions policies what future emissions will look like. A climate model is then used to calculate how those future emissions will increase global temperatures and what the impacts will be (such as higher sea levels). Part I showed that there are scientific uncertainties at this stage. The next step is to try to estimate how humans will respond to those impacts (for instance, by building higher sea walls). The model then needs to include the cost of that response and the costs of impacts that remain after such efforts at adaptation (such as storm surges higher than the sea wall). Finally, all of these future costs need to be discounted to present value to produce the ultimate estimate of the costs of climate change. Every step of this

damages make the use of 'best guess' climate scenarios to dictate optimal mitigation investment pathways inappropriate in a policy context." Megan Ceronsky et al., Checking the Price Tag on Catastrophe: The Social Cost of Carbon Under Non-Linear Response 17 (Hamburg Univ. \& Ctr. Marine \& Atmospheric Sci., Working Paper FNU-87, 2011); see also Robert S. Pindyck, Climate Change Models: What Do the Models Tell Us?, 51 J. ECON. LiTERATURE 864, 869-70 (2010).

217. Kolstad et al., supra note 211 , at 212.

218. An alternate approach to estimating damages, based on a study of the impact of temperature changes on economic productivity, finds substantially higher damages even at low levels of climate change. See Marshall Burke et al., Global Non-Linear Effect of Temperature on Economic Production, NATURE (Oct. 21, 2015), http://www.nature.com/nature/journal/v527/n7577/ full/nature $15725 \mathrm{html}$. 
process involves uncertainties that different models resolve in different ways. ${ }^{219}$

Three models have been particularly influential, and as we will see, have been used by the federal government to determine the social cost of carbon. ${ }^{220}$ Each one involves different assumptions about climate adaptation, different treatment of catastrophic outcomes, and different formulas for estimating the damages for any given amount of climate change. The first model (DICE) is middle-of-the-road, the second (FUND) provides optimistic estimates of the cost of climate change, while the third (PAGE) is the most pessimistic.

\section{The Dynamic Integrated Climate-Economy Model (DICE)}

The problem with estimating future damage from climate change is that future temperatures may ultimately be outside the range of historic variations. For instance, we cannot be sure how agricultural production in various areas will be impacted by weather that is unprecedented in the historical record. The models deal with this problem by using the amount of projected carbon emissions plus a climate model to project the global weather change. If the extent of change is within the historical record, the estimate of damages can then be based on empirical studies such as comparison of crop yields in average years with unusually hot years. Then some kind of mathematical formula can be used to extrapolate to higher temperatures. For instance, we might estimate the damages for a $1^{\circ} \mathrm{C}$ increase empirically, and then forecast that damages at $2^{\circ} \mathrm{C}$ would be twice as large and damages at $4^{\circ} \mathrm{C}$ would be four times as large.

The DICE model illustrates how this estimation process works. ${ }^{221}$

219. The three models discussed in this section are typical in using computer simulations to calculate these estimates. A few researchers have recently devised models that can be solved as equations rather than using simulations. See Christian P. Traeger, Closed-Form Integrated Assessment and Uncertainty (Ctr. for Econ. Studies \& Info Inst., Working Paper No. 5464, Aug. 2015), available at http://ssm.com/abstract $=2643293$. It remains to be seen whether this novel approach will gain traction in the climate economics community.

220. INTERAGENCY WORKING GRP. ON SOC. COST OF CARBON, TECHNICAL SUPPORT DOCUMENT: SOCIAL COST OF CARBON FOR REGULATORY IMPACT ANALYSIS UNDER EXECUTIVE ORDER 12866, at 1,5 (2010) [hereinafter INTERAGENCY WORKING GROUP], available at http://www3.epa.gov/otaq/climate/regulations/scc-tsd.pdf. For an argument that existing models overestimate damages, see Jason S. Johnston, Beyond the Social Cost of Carbon: The Real Economic Lessons About the Determinants of Harm from Changing Climate and Their Implications for Climate Policy (Va. Pub. Law \& Legal Theory Research Paper, No. 61; Va. Law \& Econ. Research Paper, No. 25, 2015), available at http://ssm.com/abstract=2674766.

221. For an overview of the model, see STEven C. NEwBold, U.S. EPA, NAT'L CTR. FOR ENVTL. ECON., SUMMARY OF THE DICE MODEL 1, 2 (2010), available at 
DICE is a modified form of models of economic growth, with carbon mitigation treated as an additional form of capital investment because eliminating a ton of carbon produces benefits in the future. ${ }^{222}$ The advantage of this approach is that models of economic growth already exist; the disadvantage is that present ability to model future economic growth is itself somewhat limited. ${ }^{223}$ In the DICE model, the magnitude of carbon dioxide emitted is a function of total GDP and of carbon intensity, ${ }^{224}$ while damages are a quadratic function of temperature ${ }^{225}$ that is, they rise based on the square of the amount of warming, rather than proportionately to the additional temperature. In order to derive estimates for higher temperatures from this model, it is necessary to first benchmark the amount of damage at low temperatures that are within the range of historic variations in weather. In order to benchmark the estimates of damages, the damages are calibrated based on studies that assume a certain amount of adaptation by farmers and others, ${ }^{226}$ while

http://yosemite.epa.gov/ee/epa/eerm.nsf/vwAN/EE-0564-114.pdf/\$file/EE-0564-114.pdf. Some shortcomings seem to apply to all of the models. For instance, they do not include damages such as ocean acidification, they assume that environmental impacts are small enough that they can be compensated by additional income, and they are based on relatively weak evidence about adaptation and technological change. See Michael Greenstone et al., Developing a Social Cost of Carbon for US Regulatory Analysis: A Methodology and Interpretation, 7 REV. ENVTL. ECON. \& POL'Y 23, 4042 (2013).

222. INTERAGENCY WORKING GROUP, supra note 220, at 6. DICE was developed by William Nordhaus and his coworkers at Yale. NORDHAUS, supra note 1, at 29.

223. As William Nordhaus, the main force behind DICE, has said, the "output follows an optimistic scenario in which the horsemen of the economic apocalypse-war, pestilence, depression, and environmental catastrophe--are largely absent." NORDHAUS \& BOYER, supra note 198, at 52. More broadly:

[M]any elements, particularly the assumptions for developing countries and economies in transition, are difficult to validate or estimate and are subject to large and growing projection errors as they run further into the future. It is probably impossible to provide accurate long-run projections given the rapid rate of social, economic, political, and institutional changes Perhaps the best one can do is to heed the words of the eminent Harvard economic forecaster, Otto Eckstein, who advised that if we cannot forecast well, we should forecast often. Id. at 53 .

224. The carbon model is sufficiently simplified to be able to run on a personal computer, unlike the full-scale models that require supercomputers. Id. at 56-57.

225. INTERAGENCY WORKING GROUP, supra note 220 , at 6 . Non-mathematically inclined readers may recall solving quadratic equations in school.

226. As Newbold explains:

Agriculture can serve as an illustrative example of some of the other categories not covered here. The basic strategy for calibrating the damage functions is to draw on estimates from previous studies of the potential economic losses in each category at a benchmark level of warming of 2.5 degrees Celsius, extrapolating across regions as necessary to cover data gaps in the literature. Some extrapolations were made using income elasticities for each impact category. As the authors explain, "United States agriculture can serve here as an example. Our estimate is that [the fraction of the value of agricultural output lost at 2.5 degrees Celsius] is 0.065 percent [based on Darwin et al. 1995]. . . The income elasticity of the impact index is 
the model implicitly assumes "optimistic and costless adaptation" for water systems, forestry, and fisheries. ${ }^{227}$ The model also makes some allowances for potentially catastrophic impacts, based on a survey of experts regarding the probability of such an outcome. ${ }^{228}$ However, it is not clear that the model makes sufficient allowance for potentially catastrophic impacts. For instance, simply adding the risk of a future collapse of the West Antarctic Ice Shelf to the DICE model raises the social cost of carbon by $10 \%{ }^{229}$ In the end, the reliability of the damage estimates in DICE and other IAMs is an open question; the IPCC refers to the formulas as based on "heroic extrapolations" from a "sparse set of studies.,"230

Climate models are under constant revision, and DICE is no exception. The latest round of changes to DICE illustrate how IAMs are being tweaked over time in a variety of ways. For example, the revised model recalibrates its version of carbon flows between the atmosphere, different levels of the ocean, and the biosphere. ${ }^{231}$ Essentially, the changes mean that carbon stays in the atmosphere longer and is transferred more slowly from the shallow ocean to the depths. ${ }^{232}$ The

estimated to be -0.1 , based on the declining share of agriculture in output as per capita output rises."

NEWBolD, supra note 221,Error! Bookmark not defined. at 4. Driesen points out that other xperts have significantly higher estimates of damages at $2.5^{\circ} \mathrm{C}$. See Driesen, supra note 2, at 804 .

227. INTERAGENCY WORKING GROUP, supra note 220 , at 6.

228. Id. The survey of experts asked about the chances of a high consequence event, meaning one that had the same effect on the economy as the Great Depression but lasted indefinitely, given warming of $3^{\circ} \mathrm{C}$ or $6^{\circ} \mathrm{C}$ by the end of the century. NORDHAUS, supra note 1 , at 87 . The average estimate was under $1 \%$ at $3{ }^{\circ} \mathrm{C}$ and about $3 \%$ at $6^{\circ} \mathrm{C}$, but with high variance and large differences across disciplines. Id at $86-87$. However, because of increased concerns since the time of the survey, DICE adopted the following approach:

To reflect these growing concerns, we assume the probability of a catastrophe with $2.5^{\circ} \mathrm{C}$ warming is double the estimated probability for a $3^{\circ} \mathrm{C}$ warming from the survey, that the probability associated with a $6^{\circ} \mathrm{C}$ warming is double the survey estimate, and that the percentage of global income lost in a catastrophe is 20 percent higher than the figure quoted in the survey. This implied that the probability of a catastrophic impact is 1.2 percent with a $2.5^{\circ} \mathrm{C}$ warming and 6.8 percent with a $6^{\circ} \mathrm{C}$ warming.

$I d$. at 88 . The study found that for most countries "catastrophic costs are estimated to be twice as large as all other impacts combined for a $2.5^{\circ} \mathrm{C}$ warming. Similarly, catastrophic damages are estimated to dominate impacts for higher temperature increases. Because the estimated catastrophic impacts are so uncertain, this implies great uncertainty about the overall impacts." $I d$. at 98 .

229. See Delavane B. Diaz, Integrated Assessment of Climate Catastrophes with Endogenous Uncertainty: Does the Risk of Ice Sheet Collapse Justify Precautionary Mitigation? (Stanford Univ., Working Paper No. 064.2015, 2015), available at http://papers.ssm.com/sol3/ papers.cfm?abstract_id $\mathbf{2 6 2 8 6 0 1}$.

230. Kolstad et al., supra note 211 , at 245.

231. INTERAGENCY WORKING GROUP, supra note 220 , at 5-6.

232. Id. at 6. 
revision also changes the modeling for sea level rise. ${ }^{233}$ Perhaps most importantly, the damage function is recalibrated, including addition of a separate term for damage due to sea level rise. ${ }^{234}$ The ultimate effect is that damages are lower in earlier periods but higher later on, with large increases in damages in the far future because sea level will continue to rise even after global average temperatures peak. ${ }^{235}$

\section{The Climate Framework for Uncertainty, Negotiation and Distribution (FUND)}

The second model takes a more conservative view of climate change. FUND ${ }^{236}$ treats gross domestic product (GDP) growth as a given, unlike the DICE model where carbon emissions influence later GDP. ${ }^{237}$ The model takes into account impacts along many sectors, treating each one separately. ${ }^{238}$ But as the lead economist has explained, the model does not take into account "extreme climate scenarios, biodiversity loss, and effects on economic development and political violence."239 For instance, severe, prolonged droughts could lead to political instability or even civil war in developing countries. The model takes into account adaptation explicitly for agriculture and sea level rise, and implicitly because other types of damages are assumed to decline as GDP rises and if temperature increases more slowly. ${ }^{240}$

FUND has some other interesting features. Model runs begin in 1950 to initialize the damage impacts at later dates, because in FUND the impacts in a given year are a function of earlier impacts. ${ }^{241} \mathrm{~A}$ number of values, including the value of a statistical life, the value of dry land lost to sea level rise, and the value of wetlands, are set to be proportional to GDP. ${ }^{242}$ Whether that relationship holds empirically is unclear.

Like DICE, the FUND model is evolving. The latest revision of FUND makes a number of adjustments. First, under the earlier version,

233. Id.

234. The damage function has been attacked as "quite incomplete and conjectural," and, like other models, incorporating anti-precautionary results. Driesen, supra note 2, at 803-04.

235. Id. at 7 .

236. The website for FUND is FUND - CLIMATE FRAMEWORK FOR UNCERTAINTY, NEGOTIATION AND DISTRIBUTION, http://www.fund-model.org/ (last visited Dec. 1, 2015).

237. Driesen, supra note 2 , at 7.

238. Id. at 8 .

239. Id.

240. Id.

241. Ceronsky et al., supra note 216 , at 3.

242. Id. at 5 . 
an area could continue to receive increased benefits from reduced heating costs no matter how warm the temperature got, which is unrealistic since warmer temperatures reduce heating needs. ${ }^{243}$ This problem has been fixed in the latest revision. ${ }^{244}$ Another adjustment is to reduce the estimate of the effects of sea level rise, on the assumption that the slope of land increases in some areas as one moves inland, reducing land loss. ${ }^{245}$ Consequently, increased sea level rise is estimated to result in losing a smaller acreage of land as the rising waters meet steeper terrain. The latest revision also changed the relationship between climate sensitivity and the rate of heating in a way that generally produces quicker temperature responses, so that warming is less delayed. ${ }^{246}$ The effect is to increase the social cost of carbon because harmful effects occur earlier and are subject to less discounting. ${ }^{247}$ Thus, like the other models, FUND has been subject to continual tweaks.

FUND is by far the most optimistic of the models, taking a generally sanguine view of climate change. Indeed, it shows that climate change is actually beneficial until it reaches $3^{\circ} \mathrm{C}$, and even a global temperature increase of $8^{\circ} \mathrm{C}$ causes less than a $10 \%$ loss of GDP in $2100 .{ }^{248}$ It also ignores possible catastrophic outcomes. This is a significant omission: Runs of the FUND model with modifications to reflect possible catastrophic events show major increases in the social cost of carbon. ${ }^{249}$ High climate sensitivity also amplified climate damages by a factor of two to three. . $^{250}$

FUND has been subject to substantial criticism. Critics have disaggregated the damage estimates and probed the underlying dynamics. ${ }^{251}$ They found that the differences between DICE and FUND were driven by different estimates of damages at any given temperature. ${ }^{252}$ They also found that damages in FUND were largely

243. INTERAGENCY WORKING GROUP, supra note 220 , at 8.

244. Id.

245. Id.

246. Id. at 9 .

247. Id. One review "concludes that in general, DICE assumes very effective adaptation and largely ignores adaptation costs." $I d$. at 7.

248. Id. at 9 .

249. Id. at 16-17. The one exception is shutdown of the Gulf Stream, which causes major cooling in Europe, but this cooling offsets what would otherwise be substantial warming there. Ceronsky et al., supra note 216 , at $14-15$.

250. Ceronsky et al., supra note 216 , at 15 .

251. See Frank Ackerman \& Charles Munitz, Climate Damages in the FUND Model: A Disaggregated Analysis, 77 ECOLOGICAL ECON. 219 (2012).

252. Id. at 220 . 
driven by two offsetting effects. The single largest source of climate harm in FUND is the increased cost of air conditioning, but this is offset by the increased benefits of $\mathrm{CO}_{2}$ to plant photosynthesis, increasing agricultural output. ${ }^{253}$ Critics have also argued that the estimates of agricultural costs were distorted because at some parameter values the program would attempt to divide by zero. ${ }^{254}$ And in their view, the model produced unrealistic estimates of temperature ranges, including some too hot for unprotected human beings to survive and some below the temperature of the last ice age. ${ }^{255}$ Finally, they faulted FUND for using outmoded research on agricultural yields that was nearly two decades old. ${ }^{256}$

\section{Policy Analysis of the Greenhouse Effect (PAGE)}

The third model is the most pessimistic about the costs of climate change. The PAGE model ${ }^{257}$ also treats GDP growth as a given, but it differs from the other models in allowing the relationship between GDP, temperature, and climate damage to vary across a range from a linear relationship (steady rise in damages with temperature) to a cubic relationship (damages accelerate sharply at higher temperatures) ${ }^{258}$ The model is relatively optimistic about adaptation, positing complete adaptation below a threshold, $90 \%$ adaptation above the threshold for developed countries, and $50 \%$ adaptation above the threshold for developing countries. ${ }^{259}$

The latest revision to the PAGE model moves damages from sea level

253. Id. For an introductory discussion of this effect and of estimates of impacts on agriculture, see STERN, supra note 202, at 79-86.

254. Ackerman \& Munitz, supra note 251, at 221-23.

255. Id. at 223.

256. Id. at 224.

257. A detailed description of PAGE can be found in CHRIS HOPE, THE PAGE09 MODEL: ESTIMATING ClIMATE IMPACTS AND THE SOCIAL COST OF CO2 (2010), available at http:/yosemite.epa.gov/ee/epa/eerm.nsf/rwAN/EE-0564-109.pdf/\$file/EE-0564-109.pdf.

258. INTERAGENCY WORKING GROUP, supra note 220 , at 7 . This ability to represent uncertainty was one of the main reasons for using this model in the Stern Report. See STERN, supra note 202, at 173. Stern concedes, however, that the model shares common problems with the other IAMs such as reliance on sparse data for calibration purposes. Id. at 174 .

259. INTERAGENCY WORKING GROUP, supra note 220 , at 7 . Driesen criticizes this assumption as unrealistic, saying it "seems like wishful thinking, in light of our failure to protect the people of New Orleans from the widely anticipated threat of a major hurricane such as Katrina." Driesen, supra note 2, at 805 . Nordhaus contends, however, that "managed systems are surprisingly resilient to climate changes if they have the time and resources to adapt," and that because of economic growth, the "vulnerability of today's poor countries to climate-change impacts is likely to decline significantly by the end of the twenty-first century." NORDHAUS, supra note 1 , at 145 . 
rise into a separate category, and like the other models, assumes that the worst damages from sea level rise will occur in the areas that are now closest to the water. ${ }^{260}$ The revision also provides a fuller treatment of the possibility of a tipping point. The model assumes that such a tipping point becomes increasingly likely after some threshold between $2^{\circ} \mathrm{C}$ and $4^{\circ} \mathrm{C}$ and then continues to rise with increased temperature. ${ }^{261}$ The revised model makes less optimistic assumptions than the earlier version about the potential for climate adaptation, which had the effect of increasing the social cost of carbon by about a third. ${ }^{262}$ Finally, the model takes catastrophic outcomes into account, assuming that the probability of a tipping point increases above a threshold but that the threshold and the consequences are not known completely. ${ }^{263}$

PAGE provides the highest estimates of the cost of climate change. ${ }^{264}$ For example, for a $5^{\circ} \mathrm{C}$ change, it forecasts a loss of GDP roughly twice as large as FUND, with the DICE model in the middle. ${ }^{265}$ Still, at higher temperatures, even PAGE seems unduly optimistic. For example, with $6^{\circ} \mathrm{C}$ of warming in 2100 , it projects a loss of only about $10 \%$ of GDP. ${ }^{266}$ Scientists view even a $4^{\circ} \mathrm{C}$ temperature increase as highly dangerous, with possible effects including desertification, drought, radical changes in rainfall, collapse of forests and biodiversity, and a surge in extreme weather events. ${ }^{267}$

\section{Summarizing the Models}

The following table provides a rough sense of how the models differ, based on the foregoing discussion.

260. INTERAGENCY WORKING GROUP, supra note 220, at 10.

261. Id. at 11 .

262. Id. at $10-11$.

263. Id. at 7 .

264. Using PAGE as the basis for its calculations, the Stern Report concluded that the welfare costs of climate change were very high, equivalent to a permanent cut in consumption of $5 \%$. STERN, supra note 202, at 185. The Stern Report selected the PAGE model because of its convenience in assessing risk and because it can span the ranges of calibration found in other models. Id. at 659 .

265. INTERAGENCY WORKING GROUP, supra note 220 , at 9 fig. $1 \mathrm{~A}$.

266. Id.

267. Nicholas Stern, The Structure of Economic Modeling of the Potential Impacts of Climate Change: Grafting Gross Underestimation of Risk onto Already Narrow Science Models, 51 J. ECON. PERSP. 838, 841 (2013). For this reason, Stern suggests, "the models fail to get to grips with the overall scale of the risks associated with the possible phenomena described at temperature changes of $4^{\circ} \mathrm{C}$." Id. at 843 . He particularly focuses on the possibility of massive population reductions and the potential consequences of those shifts. $I d$. at 843-44. 


\begin{tabular}{|c|c|c|c|c|}
\hline Model & $\begin{array}{l}\text { Damage } \\
\text { Function }\end{array}$ & Adaptation & $\begin{array}{l}\text { Catastrophic } \\
\text { Outcomes }\end{array}$ & $\begin{array}{l}\text { Social Cost } \\
\text { of Carbon } \\
\text { Estimates }\end{array}$ \\
\hline$D I C E$ & $\begin{array}{l}\text { Quadratic } \\
\text { function of } \\
\text { temperature }\end{array}$ & $\begin{array}{l}\text { Optimistic } \\
\text { assumptions }\end{array}$ & $\begin{array}{l}\text { Probability } \\
\text { based on } \\
\text { expert survey }\end{array}$ & Middle \\
\hline$F U N D$ & $\begin{array}{l}\text { Varies across } \\
\text { sectors }\end{array}$ & $\begin{array}{l}\text { Included } \\
\text { explicitly and } \\
\text { implicitly }\end{array}$ & Not included & Lowest \\
\hline$P A G E$ & $\begin{array}{l}\text { Varying } \\
\text { function of } \\
\text { temperature } \\
\text { (linear to } \\
\text { cubic) }\end{array}$ & $\begin{array}{l}\text { Very } \\
\text { optimistic for } \\
\text { developed } \\
\text { countries, less } \\
\text { so for others }\end{array}$ & $\begin{array}{l}\text { Explicitly } \\
\text { modeled }\end{array}$ & Highest \\
\hline
\end{tabular}

The federal government's 2010 report on the social cost of carbon gives a nice overview of the general state of these modeling efforts:

These models are useful because they combine climate processes, economic growth, and feedbacks between the global economy into a single modeling framework. At the same time, they gain this advantage at the expense of a more detailed representation of the underlying climatic and economic systems .... There is currently a limited amount of research linking climate impacts to economic damages, which makes this exercise even more difficult. Underlying [the models] ... are a number of simplifying assumptions and judgments reflecting the modelers' best attempts to synthesize the available scientific and economic research characterizing these relationships. ${ }^{268}$

To put this differently, the models reflect the best professional judgment of the modelers about how to roughly estimate climate damages. As we have seen, the models differ greatly not only in their details but in their outputs, suggesting that the experts involved in this venture are some distance from a consensus. For instance, as a federal report explains, even at lower temperatures, "the damages from FUND are well below the fifth percentile estimated by PAGE, while the damages estimated by DICE are roughly equal to the ninety-fifth 
percentile estimated by PAGE., ${ }^{269}$ Yet more dramatically, at $2^{\circ} \mathrm{C}$, the magnitude of the impact of climate change on GDP is about the same for FUND and DICE, but in opposite directions, with FUND showing an increase in GDP while DICE shows a decrease of roughly the same size.

There seems to be a disconnect between the reservations that the modelers properly acknowledge and the degree of their confidence in their conclusions. For instance, a description of the model by Nordhaus and a coauthor ${ }^{270}$ clearly communicates the uncertainties connected with modeling: "a major uncertainty" involves growth in "total factor productivity"; 271 "there are no well-established empirical regularities and very little history can be drawn upon" regarding the link between climate and the economy; ${ }^{272}$ there are "major uncertainties about the long-run trajectories of economic growth in different regions", ${ }^{273}$ regional growth models "are difficult to validate or estimate and are subject to large and growing projection errors as they run further into the future", ${ }^{274}$ and so on. ${ }^{275}$ The ultimate conclusions are stated with much greater confidence: the benefits of the Kyoto Protocol "for the United States, Japan, Russia, and China are essentially zero" until 2100 (assuming no catastrophe materializes); ${ }^{276}$ a delay of ten years in implementing mitigation "leads to a trivially small net loss"; ${ }^{277}$ limiting global emissions to 1990 levels causes a net "discounted loss of $\$ 3$ trillion"; 278 "an efficient climate-change policy would be relatively inexpensive and would slow climate change surprisingly little",;79 and the "Kyoto protocol has no economic or environmental rationale.","80 The economic and scientific uncertainties thus seemed to get little weight in the end.

269. Id. at 9 .

270. See NORDHAUS \& BOYER, supra note 198.

271. Id. at 17 .

272. Id. at 20 .

273. Id. at 47 .

274. Id. at 53 .

275. Some additional examples include statements that "there are no established methodologies for valuing catastrophic risk," that findings of climate impact are "highly conjectural" and it is difficult "to make solid estimates of the impacts of climate change," $i d$. at 71 , and that "[g]iven the lack of any comprehensive estimates, the authors have made rough estimates here of the extent to which the economy and other institutions are vulnerable to climate change," $i d$. at 86.

276. Id. at 96 .

277. Id. at 127.

278. Id. at 129.

279. Id. at 174 .

280. Id. at 177 . 
Richard Tol also exhibits a degree of overconfidence that does not seem to be supported by the evidence. He contended a decade ago on the basis of a meta-analysis that "[o]ne can therefore safely say that, for all practical purposes, climate change impacts may be very uncertain but it is unlikely that the marginal damage costs of carbon dioxide emissions exceed $\$ 50 / \mathrm{tC}$ (per ton of carbon) and are likely to be substantially smaller than that." ${ }^{, 281}$ Yet his own data showed that the marginal damage is quite uncertain, that there is a $10 \%$ chance that the damage exceeds $\$ 125$ per ton, and that the $\$ 50$ figure is the average rather than an upper limit. $^{282}$

A high level of confidence was also reflected in the Stern Report, which used the PAGE model. ${ }^{283}$ It estimates that the impact of climate change is equivalent to cutting GDP by $5 \%$ (and possibly as much as $20 \%$ ) "now and forever," so that "prompt and strong action is clearly warranted."284

Given the amount of effort and expertise that these researchers have put into creating these IAMs, as well as the huge policy significance of climate change, a tendency toward overconfidence in their findings is entirely understandable. But from a more objective perspective, it is clear that the models are tentative estimates rather than definitive analyses.

Some of the problems in the models can be solved or at least partially addressed by further research. For instance, more detailed studies of how farmers respond to droughts would help refine the cost of agricultural impacts. Models of climate change may also improve, which would be especially helpful if they provide a clearer understanding of the possible tipping points. But other difficulties are likely to be more intractable. Climate change is taking the world outside of the previous range of variability, which means that we really have no data about the impacts of

281. Richard S.J. Tol, The Marginal Damage Costs of Carbon Dioxide Emissions: An Assessment of the Uncertainties, 33 ENERGY POL'Y 2064, 2073 (2005). For discussion of the Tol study and of another meta-analysis from the same period with a roughly similar estimate of the average social cost of carbon ( $£ 35$ as opposed to $\$ 50$ ), see STERN, supra note 202 , at $322-23$.

282. Tol, supra note 281 , at 2071 . Considering peer-reviewed studies only, Table 3 showed a mean marginal cost of $\$ 50$, a $10 \%$ probability that the cost is over $\$ 125$, and a $5 \%$ probability that the result is over $\$ 245$. If we used standard confidence intervals ( $5 \%$ to $95 \%$ range), the confidence interval for the $\$ 50 / \mathrm{tC}$ estimate would go from $-\$ 9$ to $+\$ 245$, making any estimate of the level of harm quite speculative. In any event, saying that marginal damages are unlikely to be above $\$ 50$ and probably much lower is rather misleading when $\$ 50$ is actually the mean estimate.

283. The initial version of the Report did not contain a sensitivity analysis, but the published version contains such an analysis in the postscript that focuses on the significance of changes in the discount rate. See STERN, supra note 202, at 665-70.

284. Id. at xv. 
major temperature increases on human societies. The controversies over discount rates have gone on for many years and show no signs of abatement. Predicting future economic growth seems inherently difficult, because there is no way of knowing how technologies will develop or whether growth will be interrupted by wars or economic crises. In short, uncertainty about the economics of climate change seems to be a fact of life with which policymakers will just have to cope. The next section discusses how the U.S. government has tried to move forward despite these pervasive uncertainties.

\section{The Government's Estimate of the Cost of Climate Change}

The decision to calculate the social cost of carbon-that is, the net harmful effect of one ton of $\mathrm{CO}_{2}$ on the environment-was not one the government came to easily, or even voluntarily. Rather, it stemmed largely from the Ninth Circuit's decision in Center for Biological Diversity v. National Highway Traffic Safety Administration, ${ }^{285}$ which overturned new fuel efficiency standards for failure to consider the effects of greenhouse gas emissions. The court found that the failure to quantify the effect of efficiency standards in reducing carbon emissions was arbitrary and capricious. ${ }^{286}$ The court reasoned that the evidence seemed clear that the benefit was greater than zero, and the agency failed to show that the amount was so completely unknown that it could not be quantified, particularly since it had quantified other highly uncertain values such as the effect of reduced gasoline use on energy security. ${ }^{287}$ In the aftermath of Center for Biological Diversity, government agencies used a range of values for the social cost of carbon, ranging from under $\$ 20$ per ton in a Department of Energy rulemaking to values of $\$ 40$ per ton (at a $3 \%$ discount rate) to $\$ 68$ per ton (at a $2 \%$ discount rate) by

285. 538 F.3d 1172 (9th Cir. 2008). The court stated that even if the agency was authorized to base its decision on cost-benefit analysis, "it cannot put a thumb on the scale by undervaluing the benefits and overvaluing the costs of more stringent standards." Id. at 1198.

286. See id. at 1200-03. In particular, the court said,

while the record shows that there is a range of values, the value of carbon emissions reduction is certainly not zero. NHTSA conceded as much during oral argument when, in response to questioning, counsel for NHTSA admitted that the range of values begins at $\$ 3$ per ton of carbon. NHTSA insisted at argument that it placed no value on carbon emissions reduction rather than zero value. We fail to see the difference. The value of carbon emissions reduction is nowhere accounted for in the agency's analysis, whether quantitatively or qualitatively . ... By presenting a scientifically-supported range of values that does not begin at zero, Petitioners have shown that it is possible to monetize the benefit of carbon emissions reduction.

Id.

287. Id. 
EPA. $^{288}$

In 2009 the Interagency Working Group on Social Cost of Carbon (IWG) was convened to reduce the agency cacophony and provide a uniform estimate. ${ }^{289}$ The process was convened by OMB and the Council of Economic Advisors. ${ }^{290}$ The key participants were EPA and the agriculture, commerce, energy, transportation, and treasury departments. ${ }^{291}$

In some ways the effort was not very ambitious, in that the government decided to use the three models discussed above rather than developing its own model. ${ }^{292}$ It chose those three models because they are frequently cited in the peer review literature and by the IPCC. ${ }^{293}$ The IWG recognized the incomplete and very uncertain nature of the models. ${ }^{294}$ But given the lack of good data about the connection between climate and economic impacts, the group was unable to identify a superior approach short of launching its own research program. ${ }^{295}$ In addition, the IWG limited itself to determining the benefits from relatively small changes in emissions, so the results do not necessarily apply in considering the benefits of major changes in global emissions policy. ${ }^{296}$

One key issue about cost-benefit analysis in the climate context is the appropriateness of including international damages. The IWG opted to include those damages because of the exceptional nature of the climate change problem. ${ }^{297}$ First, the IWG maintained, international damages must be included because of the global nature of climate change harms. ${ }^{298}$ Second, international cooperation is needed to address the

288. INTERAGENCY WORKING GROUP, supra note 220, at 3.

289. Id. at 4 .

290. Id. at 3 .

291. Id.

292. Id. at 4 .

293. Id. at 5 .

294. Id. at 8 .

295. Id. The IWG does not provide an explanation of the decision to proceed with the existing models rather than launching a new research effort. The IWG did say that the differences in models "underscore the need for a thorough review of damage functions-in particular, how the models incorporate adaptation, technological change, and catastrophic damages." Id. at 9. The IWG added that "the Federal government is committed to exploring how these (and other) models can be modified to incorporate more accurate estimates of damages." Id.

296. Id. at 2.

297. Id. at 14 .

298. Id. 
issue. ${ }^{299}$ Moreover, as the IWG noted in a separate subsection of its report, nearly all of the economics literature focused on global impacts, greatly complicating any effort to derive a purely domestic estimate. ${ }^{300}$

Although the IWG used existing models designed to estimate the social cost of carbon, it did not merely adopt modeling results from the literature. Instead, it standardized the application of the models in two respects so that the outputs of the models would be more comparable. First, it adopted a probability distribution for climate sensitivity that provided a good fit with the most recent IPCC findings. ${ }^{301}$ It chose that probability distribution because it was the only one of the distributions that was based on physical theory as opposed to mathematical convenience, and because it came closer to the IPCC findings. ${ }^{302}$ Thus, it attempted to ensure that scientific uncertainty about the degree of climate sensitivity was treated similarly in all models and corresponded as much as possible to the views of scientists.

Second, the IWG selected four scenarios for business-as-usual growth in population, wealth, and emissions, which produced $2100 \mathrm{CO}_{2}$ concentrations ranging from 612 to 889 parts per million (ppm) ${ }^{303}$ It added a fifth scenario stabilizing $\mathrm{CO}_{2}$ below $500 \mathrm{ppm} \cdot{ }^{304}$ Like the IAMs, the models used to produce these scenarios were adapted from existing models, in this case the Stanford Energy Modeling Forum exercise $\left(\right.$ EMF-22). ${ }^{305}$

The three models differed a bit in their projections for population

299. Id.

300. Id. at 11 . Two other important decisions were not to use equity weighting (which would place special value on avoiding harm to the poorest countries) and not to consider risk aversion. See id. at 11,20 .

301. Id. at 11 .

302. Id. at 14. The model is based on the assumptions that climate sensitivity would be $1.2^{\circ} \mathrm{C}$ absent feedback effects, and that the feedback effects are proportional to temperature and normally distributed. Id. As compared with the IPCC results, however, the distribution somewhat underestimated the odds of a sensitivity below $1.5^{\circ} \mathrm{C} . I d$.

303. Id. at 15. Different scenarios for emissions growth under business as usual primarily stem from uncertainty about future economic growth. See NORDHAUS, supra note 1, at 34 .

304. INTERAGENCY WORKING GROUP, supra note 220 , at 15.

305. Id. The IWG pointed to some caveats:

First, EMF FAU scenarios represent the modelers' judgment of the most likely pathway absent mitigation policies to reduce greenhouse gas emissions, rather than the wider range of possible outcomes. Nevertheless, these views of the most likely outcome span a wide range, from the more optimistic (e.g. abundant low-cost, low-carbon energy) to more pessimistic (e.g. constrains on the availability of nuclear and renewables). Second, the socio-economic trajectories associated with a $500 \mathrm{ppm}$ concentration scenario are not derived from an assessment of what policy is optimal from a benefit-cost standpoint. Rather it is indicative of one possible future outcome.

Id. at $16-17$. 
increases but more in their projections of $2100 \mathrm{GDP}$, which ranged from about ten times down to about six times the GDP in $2000{ }^{306}$ Thus, the models all suggest that the world will be much richer by the end of the century, but they vary substantially in just how much richer. The scenarios also produced very different values in the modeling runs. What this means is that the social cost of carbon depends heavily on what assumptions are made about future energy use and efforts to control emissions. For example, using a 3\% discount rate, the FUND model produced 2010 carbon costs of about zero in one scenario but over $\$ 10$ in another; DICE produced between $\$ 22$ and $\$ 35.80$ per ton, depending on the scenario for emissions growth. ${ }^{307}$ Thus, in one scenario, FUND says that it is not worth spending anything to prevent climate change, whereas in another scenario FUND says that we should spend up to $\$ 10$ to eliminate a ton of carbon. To get an idea of the magnitudes involved, the United States emitted about 5.5 billion tons of carbon in $2013 .^{308}$ Under the DICE model, those emissions produced somewhere between $\$ 110$ and $\$ 196$ billion in harm. ${ }^{309}$ Thus, it would have been worth spending at least $\$ 100$ billion-but possibly twice as much-to eliminate the emissions in that year alone. ${ }^{310}$

There is a subtle but important point involved in the use of the emission scenarios to determine the harm of an additional ton of carbon. One might think from the reference to the social cost of carbon, and from the explanation that this measures the harm caused by an additional ton of carbon, that the social cost of carbon is a fixed amountsomething we could calculate based only on information about the present state of the world if we understood the economics and science completely. But determining the social cost of a ton of carbon emitted today requires us to look at every point of time while that carbon is in the atmosphere and determine the incremental harm of an additional ton at that moment.

Thinking about tipping points is one way of seeing why this might be true. Suppose that at a certain level of carbon in the atmosphere (which we can only estimate), the global temperature increase will cross a

306. Id. at 16 .

307. Id.

308. See U.S. Energy-Related Carbon Dioxide Emissions, U.S. ENERGY INFO. ADMIN, http://www.eia.gov/environment/emissions/carbon/ (last visited Oct. 21, 2015).

309. This figure is derived by multiplying the total amount of emissions by the upper and lower figures for DICE cited above ( $\$ 22$ and $\$ 35$ ).

310. It actually would be worth spending more than that, because eliminating the carbon emissions means burning less coal and gasoline, which would reduce other types of air pollution. 
tipping point resulting in huge economic harm. Now consider two scenarios. In one scenario, due to a technological breakthrough, the fossil fuel industry is phased out in ten years. As a result, the world never comes near the tipping point. This means that emitting more carbon now is going to cause limited harm. In the other scenario, there is no technological breakthrough and society will come close to the tipping point because of future emissions. In that case, additional emissions today are dangerous because they increase the risk of hitting the tipping point. The increased danger of tipping in the second scenario means a higher social cost of carbon in the second scenario. In short, to know how much harm would be caused by emitting more carbon today, it is necessary to know how high future emissions are going to be because those future emissions determine how close the world comes to a tipping point.

This is something of an oversimplification, but the point remains valid under a more careful analysis. Temperature increases are approximately proportionate to the total amount of carbon in the atmosphere. ${ }^{311}$ But the harm caused by that temperature change changes at different rates depending on how high the temperature already is: The relationship is non-linear so that an extra tenth of a degree causes far more damage at $4^{\circ} \mathrm{C}$ than at $1^{\circ} \mathrm{C} .{ }^{312}$ For that reason, to figure out the harm that an additional ton released today will cause at each moment in the future, we need to know how much total carbon is in the atmosphere at that later moment, which depends on emissions between now and then. In short, the social cost of carbon today depends on the emissions trajectory of the future.

As discussed earlier, the discount rate is also a crucial parameter in determining the social cost of carbon. The IWG carefully considered the choice of discount rates. ${ }^{313}$ It concluded that a 3\% rate was most defensible, but that reasonable arguments could be made for rates of $2.5 \%$ and $5 \%{ }^{314}$ Hence, although the IWG views the $3 \%$ discount rate as the norm, it emphasized the "importance and value of considering the full range. ${ }^{\prime 315}$ The IWG also believed it was useful to provide the cost

311. See H. Damon Matthew et al., The Proportionality of Global Warming to Cumulative Carbon Emissions, 459 NATURE 829 (2009). The linearity of the relationship is particularly evident in Figure 3.

312. For instance, in DICE, the relationship is quadratic (depending on the square of the temperature) rather than linear (proportional to temperature).

313. INTERAGENCY WORKING GROUP, supra note 220, at 17-23.

314. Id. at 23. Stern argues that current discount rates are too high because of unwarranted faith in the prospects for future economic growth. Stem, supra note 267, at 851 .

315. INTERAGENCY WORKING GROUP, supra note 220 , at 3. 
corresponding to the ninety-fifth percentile of the model run estimates (at a $3 \%$ rate). This was intended to take into account the possibility of less likely but very damaging outcomes.

The IWG ran the models numerous times in all scenarios using all three IAMs (PAGE, DICE, and FUND), producing forty-five probability distributions of the social cost of carbon for any given year (three models times three discount rates times five scenarios). ${ }^{316}$ The models and scenarios were then given equal weight and averaged to produce three combined probability distributions of the social cost of carbon in each year (three distributions because of the three discount rates). ${ }^{317}$

To take into account the possibility of improbable but very damaging outcomes, the IWG also decided to report the ninety-fifth percentile at its preferred 3\% discount rate-that is, a value that had only a $5 \%$ chance of being too low. ${ }^{318}$ Thus, the estimates using the ninety-fifth percentile reflected the possibility that the cost of climate change would be higher than predicted by the models, either because of higher-thanpredicted carbon sensitivity or because of unexpectedly high costs due to warming. Thus, this estimate was more risk-averse than the others.

The following table provides the results from a 2015 update.

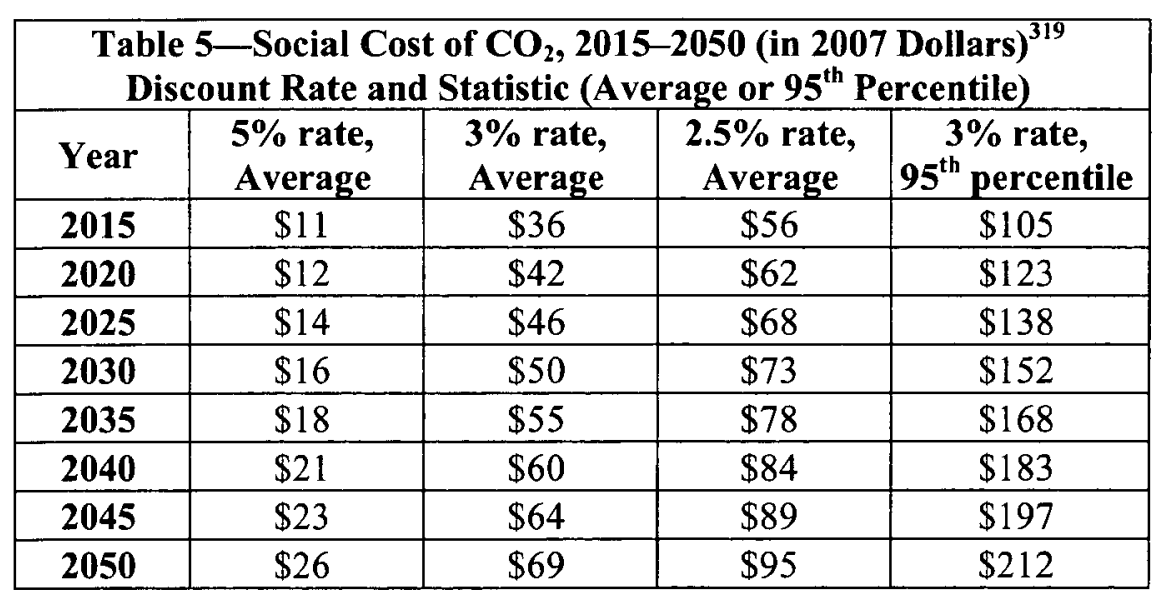

316. Id. at 25 . The $3-5 \%$ range seems to fit reasonably well with Nordhaus's preferred $4 \%$ rate based on the cost of capital. See NORDHAUS, supra note 1, at 188 .

317. INTERAGENCY WORKING GROUP, supra note 220 , at 3.

318. Id.

319. Id. at 13 tbl.2 (deleting 2010 row as no longer relevant). These results can be translated into carbon prices for gasoline: Each dollar of social cost equates to a penny a gallon worth of climate harm. See Driesen, supra note 2, at 805 . Note that a gallon of gasoline contains about twenty pounds of carbon dioxide. See NoRDHAUS, supra note 1, at 19. 
Notice that the numbers are quite different across each row, depending on the discount rate. ${ }^{320}$ But the number in each column rises over the years, roughly doubling from 2015 to 2050 . This illustrates the point discussed earlier: The damage done by an additional ton of carbon increases as additional emissions are later added to the atmosphere. In general, these figures imply that climate impacts in the near future will be moderate but that it is worth adopting a measured response today, whereas more severe future impacts are still too far in the future to make a major economic difference from the perspective of the present.

The final column combines a $3 \%$ discount rate with the ninety-fifth percentile estimate, thereby providing a safety margin to account for the risk that we will be unlucky and that climate change will turn out to be on the high end of the range rather than in the middle. This column attempts to be responsive to one of the key economic factors discussed earlier: The extent to which we should pay more to eliminate climate change as insurance against the risk of "unlucky" outcomes due to high feedback.

Commendably, the IWG provided a lengthy discussion of the limitations of its analysis, which it called "provisional and subject to further refinement (and possibly significant change). ${ }^{, 321}$ In particular, the report highlighted the lack of adequate consideration of potential catastrophic damages and of risk aversion. ${ }^{322}$ It also emphasized the possibility of spillover effects between regions: For instance, in highwarming scenarios, water scarcity would impact billions of people (about half of the global population) and food scarcity could impact about a hundred million, with millions relocating as climate refugees. ${ }^{323}$

The government has continued its efforts to better estimate the costs

320. Wagner and Weitzman argue for a $2 \%$ rate based on the long-run return on risk-free assets such as T-notes. WAGNER \& WEITZMAN, supra note 37 , at 68-69.

321. INTERAGENCY WORKING GROUP, supra note 220, at 29.

322. Id. at $28-29$.

323. Id at 32-33. For a detailed discussion of the possible spillovers, see ANDREW GuzMAN, Overheated: The Human Cost of Climate Change (2013). Dean Guzman's conclusion is that these spillovers may be very serious indeed:

As we make decisions about how to respond to climate change we must not lose sight of the very real possibility that it will have a cataclysmic impact on the way we live. I do not mean that there will be serious economic effects or that there will be modest numbers of additional deaths - these impacts are already happening. I mean that we should be worried that climate change may kill tens of millions or hundreds of millions and severely disrupt the lives of perhaps billions.

Id. at 1 . For example, he says, "[t]he already fragile coexistence of nations in the Middle East could collapse as states in the region compete for limited and shrinking water resources." Id. at 11 . For a discussion of the possible effect of climate change on regional stability and conflict, see $i d$. at 13271 . 
of climate change. A 2015 report by EPA ${ }^{324}$ provides sector-by-sector analysis of climate impacts. It estimates, for instance, that mitigation would result in cost savings by 2100 of $\$ 4.2-\$ 7.4$ billion in the form of avoided road maintenance. ${ }^{325}$ Other savings include $\$ 10-\$ 34$ billion in reduced power system costs by $2050,12,000$ fewer deaths in heat waves in 2100 , about half as many severe droughts in that year and would save $\$ 110$ billion at that time in the form of workers who would otherwise be unable to work due to heat waves. ${ }^{326}$ Continuing to refine such estimates will be important.

In principle, to the extent that the government makes use of costbenefit analysis, including the social cost of carbon in the analysis should lead to the adoption of better (and more climate protective) policies. It is not clear, however, to what extent the social cost of carbon exercise actually has lead to adoption of different policies. ${ }^{327}$ Apparently, the social cost of carbon, while not insignificant compared to other regulatory impacts, was generally not enough to change a policy from a positive cost-benefit analysis to a failing one, or vice versa. ${ }^{328}$ However, the social cost of carbon was enough to tip the balance in considering a new vehicle fuel efficiency rule. ${ }^{329}$

The Clean Power Plan, the Obama Administration's most ambitious effort to reduce emissions, exemplifies the use of the social cost of carbon. The Regulatory Impact Assessment (RIA) offers analysis of regulatory benefits with various options for interest rates. Using the IWG's preferred 3\% rate for carbon, the RIA found carbon reduction benefits of $\$ 25$ per ton in $2025 .{ }^{330}$ If a $7 \%$ rate is applied to co-benefits,

324. ePa, Climate Change in the United States: Benefits of Global action (2015), available at $\mathrm{http} / / / \mathrm{www} 2$. epa.gov/sites/production/files/2015-06/documents/cirareport.pdf.

325. Id. at 6 .

326. Id. at 8-9.

327. One recent study, however, found little evidence that the social cost of carbon had affected policy outcomes. See Robert W. Hahn \& Robert A. Ritz, Does the Social Cost of Carbon Matter?, 44 J. LEGAL STUD. 229 (2015).

328. Id. at 236-37. At least through 2011 , agencies did not employ the social cost of carbon in the primary cost-benefit analysis used to justify regulations and instead used it only in sensitivity analysis. See Jonathan S. Masur \& Eric A. Posner, Climate Regulation and the Limits of CostBenefit Analysis, 99 CALIF. L. REV. 1557, 1561 (2011). After considering fourteen regulations involving the emissions reductions, Posner and Masur report that the analyses "typically report a range of SCCs, with the statement for the most recent regulations using the IWG's figures." Id. at 1576. But "they all exclude the SCCs from the actual cost-benefit analysis, instead merely reporting them or using them in a sensitivity analysis." Id.

329. See Jay G. Stirling, How to Deal with Hornets: The Administrative Procedure Act and the Social Cost of Carbon, 100 IowA L. REv. 853, 855-56 (2015).

330. EPA, Regulatory IMPACt ANALYsis FOR the Proposed Carbon POllution GUIDELINES FOR EXISTING POWER PLANTS AND EMISSION STANDARDS FOR MODIFIED AND 
the total benefits for that year are $\$ 53-\$ 84,{ }^{331}$ meaning that the cobenefits are $\$ 28-\$ 59$ - either about the same as the carbon benefits or twice as large. With a smaller discount rate applied to health benefits, co-benefits loom even larger. ${ }^{332}$ Still, the carbon benefits are not an inconsiderable part of the total benefits. Of course, if we instead focus on the risk-averse ninety-fifth percentile figures, the carbon benefits go up dramatically to $\$ 92$. The estimated compliance costs were much lower than any of these figures (in the range of $\$ 4-\$ 7$ per ton), ${ }^{333}$ so that the proposal would have been justified in terms of either carbon benefits alone or co-benefits alone.

\section{Assessing the Application of Cost-Benefit Analysis to Climate Change}

Efforts to establish the social cost of carbon have received mixed reviews, with criticisms coming from a variety of directions. There have been substantial arguments that the IWG's estimates are too low. ${ }^{334}$ But although they complain that the results are too low, ${ }^{335}$ environmentally oriented commentators have often viewed the IWG effort as at least a step in the right direction. ${ }^{336}$ The attempt to set a social cost of carbon had strong support from the Environmental Defense Fund. ${ }^{337}$ While also

ReCONSTRUCTEd POWER PLANTS, at ES-18 tbl.ES-6 (2014), available at http://www2.epa.gov/ sites/production/files/2014-06/documents/20140602ria-clean-power-plan.pdf. For simplicity, the discussion in the text focuses on the Option 1 portion of the table.

331. Id.

332. Id.

333. Id. at ES-21 tbl.ES-8. EPA concluded:

The EPA could not monetize some important benefits of the guidelines. Unquantified benefits include climate benefits from reducing emissions of non- $\mathrm{CO}_{2}$ greenhouse gases and co-benefits from reducing exposure to $\mathrm{SO}_{2}, \mathrm{NO}_{\mathrm{x}}$, and hazardous air pollutants (e.g., mercury and hydrogen chloride), as well as ecosystem effects and visibility impairment. Upon considering these limitations and uncertainties, it remains clear that the benefits of this proposal are substantial and far outweigh the costs.

Id. at ES-20.

334. See Melissa J. Luttrell, The Social Cost of Inertia: How Cost-Benefit Incoherence Threatens to Derail U.S. Climate Policy, 25 Duke ENVTL. L. \& POL'Y F. 131, 170-82 (2014); Masur \& Posner, supra note 328 , at 1581 (finding although other errors were in the opposite direction, "[m]any of [the IWG's] errors are likely errors of underestimation").

335. See Driesen, supra note 2, at 773.

336. Luttrell, for instance, while preferring a more qualitative approach, sees the effort as in some ways improving on the government's general approach to cost-benefit analysis. Luttrell, supra note 334, at 183. Similarly Wagner and Weitzman contend that the IWG's estimate "is a good start, but it's still far from assessing the full costs of global warming" and "can only be considered a lower bound." WAGNER \& WEITZMAN, supra note 37, at 37.

337. See Over 120,000 Stand Up for a Social Cost of Carbon, ENvTL. Def. Fund (Feb. 26, 2014), http://www.edf.org/media/over-120000-stand-social-cost-carbon. 
arguing for a higher number, Natural Resource Defense Council officials still view the IWG's work favorably: "Of course, the government should still use its SCC estimate, because a low number is better than no number." ${ }^{338}$ For similar reasons, commentators have called for the use of the social cost of carbon, despite its uncertainty, in decisions by federal land managers that could increase carbon emissions. ${ }^{339}$

On the other hand, IAMs and the IWG estimates based on them have come in for some harsh criticism from commentators who are otherwise friendly to cost-benefit analysis. Although they support the use of costbenefit analysis in normal regulatory situations, legal scholars Jonathan Masur and Eric Posner argue that the degree of uncertainty and the inherently international nature of the climate problem prevent the useful application of cost-benefit analysis. ${ }^{340}$ They fault the IAMs for using weakly defended assumptions about future economic growth and technological change. ${ }^{341}$ Overall, they consider the IAMs to be "crude and inconsistent," and fault the models other than DICE for lack of transparency. ${ }^{342}$ Masur and Posner dismiss the damage function in DICE as "essentially a guess," 343 a charge that may have some validity. ${ }^{344}$ They then conjecture that "the models differ in large parts because their authors chose arbitrarily different damage functions; therefore the SCC [social cost of carbon] just reflects the average of these three guesses."

338. Laurie Johnson, The Social Cost of Carbon: Playing Catch Up to the IPCC, NRDC SWITCHBOARD (Apr. 22, 2014), http://switchboard.nrdc.org/blogs/ljohnson/ the_social_cost_of_carbon_play.html.

339. See Mark Squillace \& Alexander Hood, NEPA and Climate Change, 42 ENVTL. L. 469, 516 (2012). They advocate the use of the social cost of carbon as "the best basis for estimating the climate-related costs associated with agency actions." Id.

340. Masur \& Posner, supra note 328, at 1563.

341. Id. at 1581-83. Stern presents a similar criticism. See Stern, supra note 267, at 845.

342. Masur \& Posner, supra note 328 , at 1583 . For a similar view of the weaknesses of the models from the other end of the spectrum, see Driesen, supra note 2, at 780-81 ("All of this uncertainty means that the quantitative risk assessment at the base of an estimate of carbon abatement's benefits involves an incomplete and unreliable estimate."). Driesen also maintains that, "[a]bsent good data or a solid basis for extrapolation from data, expert judgment is unlikely to be very good." Id. at 782 .

343. Masur \& Posner, supra note 328 , at 1584.

344. The IPCC considers the damage functions in existing IAMs to be "of low reliability." Kolstad et al., supra note 211 , at 212.

345. Masur \& Posner, supra note 328 , at 1596 . They also contend that using the ninety-fifth percentile from the climate runs is misleading because FUND does not consider the possibility of catastrophic outcomes. Id. at 1584-85. Moreover, they argue, it was a mistake to use all three models: "[T]he extreme discrepancies between these three models-FUND and DICE are essentially inconsistent with one another-does not inspire confidence. It seems likely that one of the three models is simply incorrect and is skewing the overall results improperly." Id. at 1585 . 
In another vein, Masur and Posner also criticize the IWG for making political judgments on matters that should be left to Congress. For instance, they consider the question of whether to include harm to foreigners to be a sensitive political question that should be made by elected officials. ${ }^{346}$ The appropriate action for the United States depends in part on what other countries do, and judgments about such matters are political rather than technical. ${ }^{347}$ In short, they say, while decisions should consider costs and benefits, policymakers "will have to make an all-things-considered moral and political judgment that addresses scientific uncertainty, the value of foreign lives, the likely reactions of foreign countries, and the other imponderables for which cost-benefit analysis not suited., ${ }^{348}$

Economist Robert Pindyck is even more sharply critical of the use of IAMs. He asks what these models have told us, and responds "very little." ${ }^{349}$ Like Masur and Posner, he sees a large range of possible parameter values and modeling choices, and concludes that their reasonableness is "very much in the eyes of the modeler." 350 For instance, he views the choice of a discount rate as very much a value judgment rather than a purely technical determination. ${ }^{351}$ And "[w]hen it comes to the damage function," he says, "we know almost nothing, so developers of IAMs can do little more than make up functional forms and corresponding parameter values., 352

Pindyck is even more outspoken in a more recent paper, where he says that "calling these models 'close to useless' is generous." ${ }^{\text {"353 }} \mathrm{He}$

346. Id. at 1596.

347. Id. at $1596-97$.

348. Id. at 1597. In the absence of congressional action to set a social cost of carbon, Masur and Posner contend,

the Obama administration should suspend his cost-benefit analysis executive order for regulations touching on climate change and order agencies to use a figure that will encourage other countries to enter a climate treaty (if in fact such a figure exists), and initiate notice-andcomment rulemaking as a second-best means of addressing the political questions that costbenefit analysis cannot answer.

Id. at 1599.

349. Pindyck, supra note 216 , at 3.

350. Id. at 5 .

351. Id. at 7 .

352. Id. at 11. Later, he adds that " $[t]$ he bottom line here is that the damage functions used in most IAMs are completely made up, with no theoretical or empirical foundation." Id. at 13 . He views this as a relatively minor problem for low levels of temperature change but very problematic for higher ones: "Putting $T=5$ or $T=7$ into [a damage formula] is a completely meaningless exercise." Id.

353. Robert Pindyck, The Use and Misuse of Models for Climate Policy 1 (Mass. Inst. Tech., Working Paper No. 21097, 2015). 
contends that an IAM model "can be used to obtain almost any result one desires, and thereby legitimize what is essentially a subjective opinion about policy." ${ }^{354}$ Worse, he says, using IAMs to set the social cost of carbon or make policy decisions is "in some ways dishonest, in that it creates a veneer of scientific legitimacy that is misleading. ${ }^{355} \mathrm{He}$ argues that the social cost of carbon is basically a product of two factors: the choice of discount rate $^{356}$ and the likelihood of catastrophic outcomes. $^{357}$

These criticisms may be overblown, but it seems clear that costbenefit analysis cannot be more than one possible input when setting targets for greenhouse gas reduction-that is, for macro-level decisions about climate policy. Despite all the efforts of their creators, the models are simply too weakly justified and too varied to provide enough confidence in their estimates.

Given the weakness of these models, several economists argue that climate policy should not be based on cost-benefit analysis; instead, the goal should be to limit temperature increases sufficiently to prevent unacceptable risks of catastrophic outcomes. ${ }^{358}$ If this precautionary approach is taken, a figure for the social cost of carbon for use in costbenefit analysis can be reverse-engineered from the trajectories needed to reach the target. ${ }^{359}$ Part IV returns to this idea later, but first provides

\section{4. $I d$.}

355. Id. at 3. In a similar vein, but from a much different perspective, Kysar speculates that the cost-benefit analysis of climate change is appealing "only because the ritual comports with our deeply ingrained desire to imagine our most difficult policy choices as purely scientific or technical in nature." Kysar, supra note 62, at 31.

356. As he puts it, "there is hardly any need for a model; decide on the discount rate; and you pretty much have an estimate of the [social cost of carbon]." Pindyck, supra note 353, at 10.

357. Pindyck explains:

How do we know that the possibility of a catastrophic outcome is what matters for the SCC? Because unless we are ready to accept a discount rate that is very small, the "most likely" scenarios for climate change simply don't generate enough damages-in present value termsto matter. That is why the Interagency Working Group, which used a 3 percent discount rate, obtained the rather low estimate of $\$ 33$ per ton for the [social cost of carbon].

Id. at 11 .

358. See, e.g., Ceronsky et al., supra note 216 , at 19 ("The appropriate response, [rather than relying in IAMs] is the creation of robust policies that will be suitable given a range of potential impact scenarios. Specifically, this means finding the most efficient way of keeping open the possibility of stabilizing greenhouse gases at a low atmospheric concentration (not much higher than that of today) in the event that high damage scenarios are not ruled out as the field of study advances.").

359. Pindyck argues that a rough estimate of the social cost of carbon can be determined by simply estimating the level of carbon reductions necessary to achieve the desired level of precaution, calculating a credible estimate of the benefits using reasonable ranges of the discount rate and other parameters, and then dividing the total benefits by the number of tons. See Pindyck, 
a synthesis and analysis of the case studies.

\section{LESSONS FROM THE PAST AND DIRECTIONS FOR THE FUTURE}

\section{A. Implications of the Case Studies}

The previous two parts of this Article have considered the two basic approaches to climate policy represented by the precautionary principle and cost-benefit analysis. The precautionary principle requires costeffective measures to address serious but uncertain risks. Case studies involving the precautionary principle included the EPA endangerment finding, the listing decision of the polar bear as a threatened species, and the selection of a $2^{\circ} \mathrm{C}$ target for climate policy by the international community. The alternative approach, cost-benefit analysis, requires that costs and benefits of climate policy be quantified. The IWG's estimate of the social cost of carbon provided the case study for that approach.

The four case studies are interesting in their own right, but they also are illuminating in terms of the problem of making policy in the face of uncertainty. Consider first the case studies of the precautionary principle. The federal government's implementation of the precautionary principle has not seemed to pose major difficulties. In the endangerment finding and in the polar bear listing, the government was required by statute to adopt a precautionary approach, focusing on whether climate change presented a serious risk, and it was able to reach this conclusion without any special difficulties in both settings. But the use of the precautionary principle seems more difficult when the context is setting a temperature climate for the planet. This is a line-drawing exercise, and the precautionary principle does not provide clear guidance on where risk becomes high enough to mandate action (or on just how much of a response is mandated). Thus, the $2{ }^{\circ} \mathrm{C}$ target endorsed through international negotiations, while perhaps not unreasonable, rests on grounds that remain opaque. ${ }^{360}$

In terms of the alternative to the precautionary principle, cost-benefit analysis, Part III made it clear that uncertainty permeates the economics of climate change. The critical uncertainties that seem to drive differences in the final outcome of analysis relate to the discount rate and the likelihood of catastrophic outcomes. As the case study showed, the IWG was forthright about these difficulties, which make any specific

supra note 353 , at 12 .

360. See supra Part II.B. 
estimate of the social cost of carbon very tentative at best. Despite these uncertainties, it remains clear that the social cost of carbon is not zero. To the extent that agencies are committed to the use of cost-benefit analysis in their regulatory actions, there seems to be a strong argument for finding some reasonably plausible figure, but what figure to use is hotly disputed.

Given the desirability of coming up with some figure, the IWG took a reasonable enough approach. Picking the FUND, DICE, and PAGE models had several advantages. The IWG's explanation of its action focused on the prominence of these articles in the economics literature. ${ }^{361}$ But these models also have the advantage of spanning a range of perspectives, from the FUND model (minimizing the seriousness of the climate problem) to the PAGE model (taking a more precautionary approach). And by using existing models rather than designing its own, the IWG may have helped immunize itself from charges of slanting its own model to support preconceived policy positions. Thus, the resulting social cost of carbon estimates could reasonably be defended as based on an objective (policy neutral) approach. Naturally, no one was going to be completely happy with the results of the analysis, but at least one could credibly argue that all viewpoints had been given some weight. Thus, the IWG's estimate, while surrounded by great uncertainty, had something to be said for it as a pragmatic solution.

In short, the precautionary principle seems reasonably good at identifying situations where climate change is a serious enough problem to justify some response. But it still remains quite unclear how we should decide on the magnitude of the response. It is hard to quarrel with the view that " $[\mathrm{w}] \mathrm{e}$ ought to find a sensible balance between overreaction and inexcusable inaction. ${ }^{362}$ Yet, cost-benefit analysis also seems to be unable to provide firm answers to that question, supplying a social cost of carbon that is subject to great uncertainty. Thus, neither the precautionary principle nor conventional cost-benefit analysis is capable of providing a clear answer about climate policy even if we put aside all of the broader debates over their validity.

\section{B. Future Directions}

We might make some progress in addressing climate policy by combining cost-benefit analysis with the precautionary principle. There 
are several possible ways of doing this.

The first option is a holistic analysis. One hybrid approach is to simply give decision makers the scientific data, the IAM results, and the precautionary principle, leaving it to them to make their best judgment based on all of this information. ${ }^{363}$ Perhaps this approach is the best we can do in terms of setting overall targets. However, at the implementation level, both this approach and the precautionary principle have the disadvantage of leaving lower-level decision makers with little guidance, which is likely to result in very disparate results. Given the fact that a ton of carbon poses exactly the same risks regardless of its source or what agency is regulating it, a more uniform approach seems preferable. The approaches that follow attempt to generate a carbon cost to be used in that kind of analysis.

A second option is to use cost-benefit analysis and run IAMs with low discount rates and high climate sensitivities (or more generally, with risk-averse estimates of potential impacts). ${ }^{364}$ This would generate estimates of the cost of carbon that could then be plugged into the regulatory impact analysis of proposed regulations or legislative actions. Deciding on just how precautionary to make the cost-benefit analysis involves a degree of subjective judgment, but hardly more so than with the existing estimates. Under this approach, the precautionary principle drives the IAMs.

A third option would be to bypass the IAMs when setting a target. We could then set a temperature goal using the precautionary principle, based on some rough judgment about the dangers of climate change and the range of feasible emissions reductions. The IAMs could then be used to try to identify a least-cost trajectory of emissions for achieving the goal. This would require using the climate modules and the mitigation cost modules from the IAMs, but not the damage functions or discounting. Hence 'some of the key economic uncertainties would be avoided. For purposes of cost-benefit analysis of particular regulations, we could equate the social cost of carbon with the per-ton mitigation cost along the least-cost trajectory. ${ }^{365}$ This figure, for example, could be used to set a carbon tax or incorporated in cost-benefit analyses of particular regulations. The first step in this approach would remain somewhat unsatisfactory, in terms of our ability to articulate the reasons

363. Daniel Farber, Uncertainty, 99 GEO. L.J. 901, 940-46 (2011), explores some structured uses of scenario as a way of helping policymakers work through decisions involving uncertainty about climate change.

364. See supra Part III.B.

365. See supra Part III.B. 
for setting the temperature goal exactly where we do. And it may strike some as too subjective or too political. Still, this approach is relatively transparent and avoids the need for accurate assessments of climate damages that we are in no position to make.

These approaches are promising, but it would be desirable to find a way of integrating them in order to take advantage of the strong points of each one. Consider the following proposal, which involves an iterative process using aspects of all three of the options discussed above. The analysis would begin with a modified version of the first approach in which a holistic decision is made about the temperature target. The risk of catastrophic outcomes could be taken into account by using integrated assessment models with precautionary assumptions such as high climate sensitivity and a low discount rate. Because of the uncertainties associated with the models and the amount of discretion involved in setting parameters such as climate sensitivity, the models would not be used directly to set a social cost of carbon. Instead, the decision maker could use the results of these models as part of a holistic approach to setting a target for atmospheric greenhouse gas concentrations.

The next step would be generating a figure for use as the social cost of carbon. Although the temperature target would not be based on a costbenefit framework, it is useful to have a figure for the social cost of carbon to use in making decisions about individual policies or project approvals. Here, the policy analyst could back the social cost of carbon out of that target temperature based on mitigation costs. That is, the policy analyst would determine the lowest cost emissions trajectory for achieving the greenhouse gas target. The marginal cost of the carbon mitigation measures along that trajectory would be considered the social cost of carbon. At this point, decision makers would need to assess that figure. If it seems higher than society should bear, the analysis could revert to the first step, and a higher target could be used. On the other hand, if it seems very easily manageable, it may be worth returning to the first step and adopting a more stringent emissions target in order to buy extra "insurance" against the possibility of catastrophic outcomes.

Like the government's "social cost of carbon" effort, the upshot would be a dollar amount associated with emission of a ton of carbon, which could then be plugged into cost-benefit analysis of specific regulatory decisions. It is not clear whether the resulting estimate is properly described as the social cost of carbon. Unlike the IWG's approach, it is not based on a direct estimate of how much harm is done by the added carbon pollution. On the other hand, suppose the government is considering whether to allow a project to emit 
additional carbon. If the government allows the extra emissions, it will have to compensate by reducing emissions somewhere else, in order to stay on the pathway for total annual emissions that has already been selected to minimize the risk of carbon catastrophe. So one of the costs of the project to society is the need to make additional carbon reductions elsewhere. Because approval of the project would impose this additional mitigation cost on society, that cost could be appropriately considered the social cost of carbon vis a vis that project. Using that terminology could be confusing, however, because the methodology is so different from the one currently in use. For that reason, it might be preferable to adopt a different term, such as calling it the implicit price of carbon ("implicit" because the price is derived from the greenhouse gas target).

\section{CONCLUSION}

As the case studies show, our current methodologies for establishing climate policy are decidedly imperfect. Despite the as-yet unresolved methodological problems, however, the case studies do provide some good news. First, we seem to be reasonably good at determining when climate risks are significant enough to warrant attention, using precautionary approaches. Despite the uncertainties in determining climate impacts, we do seem at the point where we can identify specific regulatory decisions where climate is the greatest concern.

Second, we now have a good sense of the contours of the central policy issues in shaping the response to climate change. In brief, the key factors seem to be (1) how much to care about the present versus the future (at least the next couple of centuries), and (2) how much to worry about possible catastrophic scenarios (including high climate sensitivity). We also have some sense of how various stances toward these issues would translate into the strength of the resulting climate policies.

Finally, despite the formidable analytic difficulties, we do seem to be muddling through, in terms of creating coherent policy. The international community seems to have come up with a temperature target (though perhaps not a very firm or completely achievable one). Agencies have successfully applied the precautionary principle to decide whether to regulate greenhouse gases from vehicles or protect polar bears. The IWG did manage to come up with an estimate for the social cost that seems to take into account a range of possible stances toward climate change. ${ }^{366}$ 
It is clear that the state of the art is a long way from having a rigorous method for identifying the best climate policy given current uncertainties. Decision makers will ultimately have to make value judgments about how much to invest in avoiding potential catastrophes and what weight to give to the interests of future generations. In developing improved methods of assessing alternative policies, the goals should be to give the decision makers as much relevant information as possible in useable form and to make the role of value judgments as transparent as possible.

Perhaps the most encouraging aspect of the situation is that we have made a great deal of progress in identifying the key sources of uncertainty. The economic models are useful, if for no other reason, because they allow us to get a sense of the relative importance of these parameters such as the relative weight for present mitigation costs versus future climate impacts, the risk of catastrophic outcomes, and the climate sensitivity. Whether or not policymakers use cost-benefit analysis, these factors all seem relevant to the decision even if only in qualitative terms. This improved understanding of the situation stops short of indicating the right policy outcome, but it does clarify just what is at stake. There are also some promising possible approaches that make use of both the precautionary principle, including the iterative approach proposed in the previous section. If, to take a somewhat jaundiced view of the situation, we view ourselves as looking for a lost object (the best climate policy) in a dark room, at least we now know the size and shape of the room. With luck, we might even find a flashlight. 
1726 